\title{
Plasmodium genomics: an approach for learning about and ending human malaria
}

\author{
José Antonio Garrido-Cardenas ${ }^{1}$ (ID $\cdot$ Lilia González-Cerón ${ }^{2} \cdot$ Francisco Manzano-Agugliaro $^{3} \cdot$ Concepción Mesa-Valle $^{1}$
}

Received: 23 July 2018 / Accepted: 19 October 2018 / Published online: 6 November 2018

(C) Springer-Verlag GmbH Germany, part of Springer Nature 2018

\begin{abstract}
Malaria causes high levels of morbidity and mortality in human beings worldwide. According to the World Health Organization (WHO), about half a million people die of this disease each year. Malaria is caused by six species of parasites belonging to the Plasmodium genus: P. falciparum, P. knowlesi, P. vivax, P. malariae, P. ovale curtisi, and P. ovale wallikeri. Currently, malaria is being kept under control with varying levels of elimination success in different countries. The development of new molecular tools as well as the use of next-generation sequencing (NGS) technologies and novel bioinformatic approaches has improved our knowledge of malarial epidemiology, diagnosis, treatment, vaccine development, and surveillance strategies. In this work, the genetics and genomics of human malarias have been analyzed. Since the first $P$. falciparum genome was sequenced in 2002, various population-level genetic and genomic surveys, together with transcriptomic and proteomic studies, have shown the importance of molecular approaches in supporting malaria elimination.
\end{abstract}

Keywords Malaria $\cdot$ Plasmodium falciparum $\cdot$ P. vivax $\cdot$ Vaccine

\section{Malaria}

Malaria is caused by protozoan parasites belonging to the genus Plasmodium. The latest WHO report (2016) estimates 216 million malaria cases and 445,000 deaths worldwide each year (World Health Organization et al. 2015). Africa is the continent most affected by malaria with $90 \%$ of the global

Section Editor: Tobili Sam-Yellowe

José Antonio Garrido-Cardenas

jcardena@ual.es

Lilia González-Cerón

lgonzal@insp.mx

Francisco Manzano-Agugliaro

fmanzano@ual.es

Concepción Mesa-Valle

cmesa@ual.es

1 Department of Biology and Geology, University of Almeria, 04120 Almeria, Spain

2 Regional Center for Public Health Research, National Institute of Public Health, Tapachula, Chiapas, Mexico

3 Department of Engineering, University of Almeria, 04120 Almeria, Spain cases; $7 \%$ percent are in Southeast Asia while less than $1 \%$ occur in Central and South America. The Eastern Mediterranean region accounts for approximately $2 \%$ of cases.

Despite Plasmodium being an ancient parasite (Carter and Mendis 2002) and the extensive knowledge gathered regarding its life cycle (Fig. 1), researchers of its biology, genetics, and epidemiology today face a challenge in tackling the threat it poses to millions of people. Plasmodium falciparum is responsible for the deadliest parasitic disease in history. Its distribution is wide although the African continent is the most severely affected - in sub-Saharan countries, it represents an enormous public health problem, since it is here where more than $90 \%$ of cases are recorded, and $91 \%$ of deaths worldwide occur, most of them children. Plasmodium vivax, on the other hand, is highly prevalent in most malarial areas, except in Africa. This species generally causes a debilitating disease although in some regions severe malaria cases have been reported (Naing et al. 2014). Other species such as Plasmodium malariae, Plasmodium knowlesi, Plasmosdium ovale curtisi, and Plasmodium ovale wallikeri (Sutherland et al. 2010) (Zaw and Lin 2017) seem to be less widely distributed, or their prevalence is underestimated. Traditionally, $P$. ovale curtisi and $P$. ovale wallikeri were considered subspecies. However, according to the Ansari manuscript (Ansari et al. 2016), which 


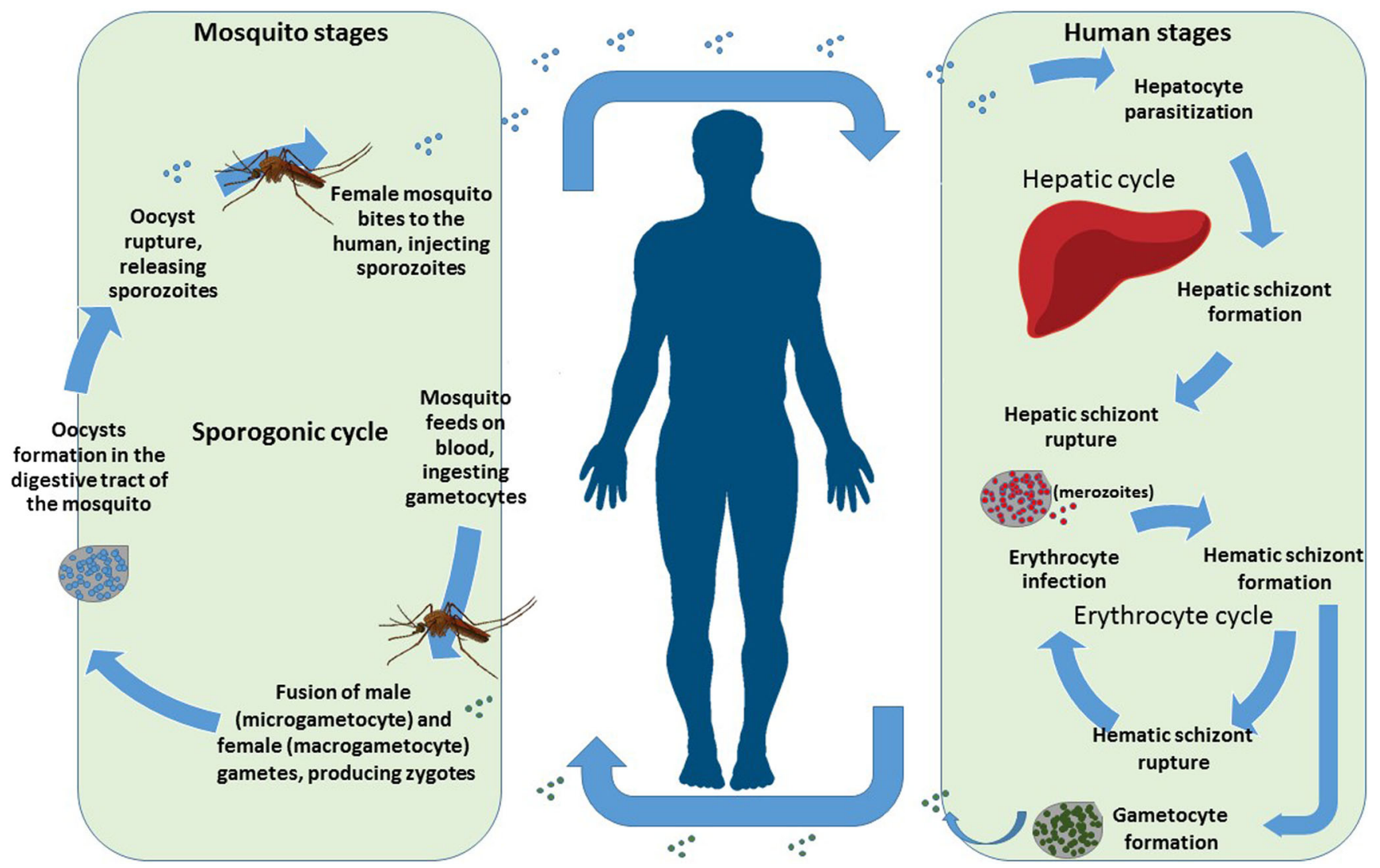

Fig. 1 Plasmodium life cycle

looked at diversity in the surface antigens together with their phylogenetic separation, it was revealed that, in fact, they are two different species. P. ovale curtisi, P. ovale wallikeri, and P. malariae can be found in Asia and, especially, in West Africa, while P. knowlesi is located in Southeast Asia. Coinfections are frequent (Zimmerman et al. 2004). Consequently, mixed infections of $P$. falciparum and $P$. vivax (Imwong et al. 2011) (Ginouves et al. 2015), or P. ovale curtisi and $P$. ovale wallikeri with $P$. malariae have been detected in patients living in areas where both species are prevalent (Dinko et al. 2013) (Fançony et al. 2012).

Plasmodium species are numerous, and all have similar life cycles with an arthropod as a vector and vertebrate host specificity. Some non-human species can infect reptiles, birds, or mammals such as rodents or apes. The Plasmodium life cycle is complex; its sexual reproduction takes place in mosquitoes of the genus Anopheles. In this phase, the parasite is briefly found as a diploid organism. In another phase, it is found reproducing asexually (schizogony) in the vertebrate or intermediate host where it has a haploid genome. In humans, the parasite has two multiplicative stages: one inside the liver cell (the exoerythrocytic phase) and another inside the erythrocyte (the intraerythrocyte phase). The cycle begins with the bite of an infected female Anopheles mosquito, which inoculates the sporozoites into the vertebrate host while feeding. These sporozoites, which remain on the skin for between 1 and $3 \mathrm{~h}$ (Ejigiri and Sinnis
2009), exhibit great mobility and hence migrate through the bloodstream (Ménard et al. 2013) (Formaglio and Amino 2015) (Acharya et al. 2017) to the hepatic parenchymal cells. From the single sporozoite invading a hepatocyte, thousands of merozoites are produced, a process that requires between 2 and 14 days depending on the Plasmodium species (Hall et al. 2005). Thus, in $P$. vivax and $P$. ovale, the hypnozoites are formed. These are dormant forms that remain in the liver cells and are responsible for relapse episodes, which can occur weeks, months, or even years later (Howes et al. 2016) (Markus 2011). Subsequently, the hepatic merozoites invade the erythrocytes, and the parasites multiply again releasing a new generation of merozoites that will invade new red blood cells - in this way, the erythrocyte asexual cycle is repeated over and over again (Silvie et al. 2008; Gilson and Crabb 2009). At this stage, the symptoms of the disease and pathology manifest. In the erythrocyte cycle, some parasites are programmed to transform into male and female gametocytes, these are the infective forms that enter the Anopheline mosquito species.

In the mosquito midgut, both female and male gametocytes are transformed into gametes (gametogenesis). This process is rapid, and recent studies by Bansal et al. (2017) have revealed the fundamental role of a calcium-dependent protein, kinase (PfCDPK2) in the transformation of male gametocytes into gametes. Zygotes mature into ookinetes, which traverse the peritrophic membrane and midgut epithelium, and then 
differentiate into oocysts that lodge on the midgut's outer surface (Barillas-Mury and Kumar 2005). The oocysts have four haploid genomes, which might be recombinants (Sinden 2015), and thousands of haploid sporozoites are developed and released into the hemocele, finally invading the salivary glands (1-3 weeks). Parasites reach the next host when the female Anopheles mosquitoes blood feed, thus completing the parasite's life cycle.

\section{Objectives}

The main objective of this work is to carry out a review of articles published on the genome of the Plasmodium parasite species capable of affecting humans. To bring to light certain aspects of malarial transmission and its parasitic interactions with vertebrate and invertebrate hosts, since 2002 (when the $P$. falciparum genome was first sequenced), a large number of studies have focused on and defined the genetics, genomics, and functional genomics of a list of genes and families related to drug resistance. This review comprises the large number of genes that encode for proteins at the interface of host-parasite interactions in order to establish new antigenic candidates for the development of novel vaccines.

\section{Epidemiology}

In addition to the four species that have historically affected humans, $P$. knowlesi was recently recognized as a further species causing human malaria. This species was first identified in 1932 as a natural parasite of macaques in Southeast Asia, and the first human case of malaria was recorded in 1965. Almost 40 years later, Singh et al. studied a large number of malaria cases produced by $P$. knowlesi in Malaysian Borneo (Singh et al. 2004a). It is now considered as an emerging Plasmodium species in the Asian continent (Herdiana et al. 2016), where numerous human cases have been recorded over the last decade (White 2008) (William et al. 2013) (Yusof et al. 2014). This is the most common type of malaria in Malaysia, with the indigenous population and travelers who enter the jungle being most affected by the parasite (Millar and CoxSingh 2015) (Barber et al. 2017). Potentially, the actual number of cases produced by $P$. knowlesi is even greater than that estimated due to the possibility of misdiagnosis - the blood stages of $P$. knowlesi are similar to those of $P$. malariae. Therefore, morphological identification is quite complicated and under complex epidemiological conditions, they might be indistinguishable from other human-affecting species (Singh et al. 2004a) (Herdiana et al. 2016) (Lubis et al. 2017).

In South America, two species were found that infect humans: $P$. simium and $P$. brasilianum. The first is almost indiscernible from $P$. vivax, and the second is indiscernible from
P. malariae. $P$. simium is a native monkey parasite and although its natural hosts (arboreal howler monkeys, wooly spider monkeys, and capuchin monkeys) are distributed throughout South America (Alvarenga et al. 2015), P. simium is located exclusively in the Atlantic forest of southern and south-eastern Brazil. The first case of human infection was described in Brazil infecting a scientific assistant exposed naturally to vector bites, probably from infectious primate malaria parasites (Deane and Deane 1992). In 2014, Costa et al. (Costa et al. 2014) reported a high prevalence of $P$. simium in monkeys inhabiting this geographical region. Between 2006 and 2016, several human malaria cases were detected in the valleys of the Atlantic forest (Siqueira et al. 2016).

Later, Brasil et al. (Brasil et al. 2017) reported a malarial outbreak in the Atlantic forest of Rio de Janeiro state during 2015 and 2016. The epidemiological data seem to indicate that these cases were due to the encroachment of humans into the monkeys' natural habitat; they therefore concluded that the zoonotic transmission of $P$. simium was unambiguous. Probably such transmission has always existed but the cases were misdiagnosed as $P$. vivax (Grigg and Snounou 2017) _ either that or $P$. simium is becoming better adapted to infecting humans.

Further mitochondrial DNA studies of Plasmodium species found in human, simian, and mosquito samples suggest that in the Atlantic Forest of Brazil, a cross-over from humans and ape species (Buery et al. 2017) is occurring.

P. brasilianum was first identified in 1908 by Gonder and Von Berenberg-Gossler, and described as a simian Plasmodium that infected several monkeys species (Guimarães et al. 2012). It was found to be distributed in Panama in the 1930-50s (Collins 2002) but there is no recent information on its prevalence and risk to humans. More than a decade ago, the species was reported to be infecting the primate Alouatta palliate (the mantled howler monkey) in Costa Rica (Chinchilla et al. 2006). In this country, the difficulty in differentiating $P$. malariae from $P$. brasillianum in simian and human samples was recently evidenced (Calvo et al. 2015; Fuentes-Ramírez et al. 2017).

The first human cases of $P$. brasilianum in the Amazonian and Atlantic forest regions of South America were recorded in 2015 by Lalremruata et al. (Lalremruata et al. 2015); these occurred in indigenous Yanomami Indians on the border between Venezuela and Brazil and resulted from anthropozoonotic transmission. It is very likely that the monkeys are acting as reservoirs for both species (Araújo et al. 2013; Figueiredo et al. 2017; Fuentes-Ramírez et al. 2017). P. cynomolgi is another primate parasite, found on the Asian continent, whose natural hosts are long-tailed macaques. The first human case was recently recorded in the Malaysian peninsula, where these apes are widely distributed (Ta et al. 2014).

All of the above threaten the eradication of malaria. Consequently, it is essential to improve diagnoses using molecular techniques as well as to strengthen the epidemiological 
studies in order to determine if the monkeys are really acting as parasite reservoirs.

\section{Clinical form and treatment}

The clinical manifestations of malaria and their evolution can vary greatly. Both depend on the particular Plasmodium species, the host's innate and acquired immunity, and the choice of a suitable and timely treatment. Malaria is usually classified into three types: asymptomatic, uncomplicated, and severe (WHO 2014).

Malaria is considered asymptomatic when blood parasites are present but there are no clinical symptoms (fever and chills) and therefore no antimalarial treatment (Lindblade et al. 2013) (Phillips et al. 2017) is administered. Mild or uncomplicated malaria presents with non-specific symptoms that may include fever and shaking chills, with parasitemia but no serious organ disturbance. This can be caused by all the Plasmodium spp. Severe malaria, on the other hand, is the most dangerous form of the disease with numerous complications such as severe anemia and multiple organ damage, including the brain (cerebral malaria), lungs, and kidneys (Bartoloni and Zammarchi 2012) (White et al. 2014). This causes high morbidity and mortality rates in African children under 5 years of age and is mainly produced by $P$. falciparum (Seydel et al. 2015) (Maitland 2016). Nonetheless, it can also be caused by $P$. vivax (Arnott et al. 2012) or P. knowlesi (Bartoloni and Zammarchi 2012) at a much lower frequency.

Immunity seems to be a determining factor in malaria symptoms. In areas of moderate to high transmission, repeated infections and continuous exposure produce partial immunity to the disease, resulting in a decrease of clinical symptoms (Filipe et al. 2007). On the other hand, it has been seen that this immunity does not depend so much on the frequency of exposure as on the maturation of the immune system itself (Lindblade et al. 2013), so that adults and children over 5 years of age living in areas of transmission of $P$. falciparum or $P$. vivax develop protective immunity against the parasite (Mueller et al. 2013). This immunity against the parasite is carried out through the control of its replication and the consequent decrease of its parasitic density (Mohan and Stevenson 1998). In areas of high transmission, anti-disease immunity develops more rapidly than in areas of low transmission, and asymptomatic infections are more frequent (Hamad et al. 2000) (Magesa et al. 2002). However, $P$. malariae, $P$. ovale curtisi, and $P$. ovale wallikeri are mostly detected as mixed infections combined with other malaria species (Rojo-marcos 2011) (Scuracchio et al. 2011) (Dinko et al. 2013). Chen et al. proposed using the term "chronic malaria" (Chen et al. 2016) for asymptomatic infections (microscopic or submicroscopic) that may persist for long periods of time (Bousema et al. 2014) and, therefore, should be considered as important reservoirs since they may contribute to the disease's transmission. Accordingly, several authors have shown the infective capacity of gametocytes in the mosquito host, even at submicroscopic levels (Schneider et al. 2007) (Ouédraogo et al. 2009). However, there are discrepancies in the results obtained regarding the role the mosquitoes play as a reservoir (Nyboer et al. 2017) (Lin et al. 2014) (Gonçalves et al. 2016). These infections are more widespread than previously thought, even in low-endemic areas, and are very common in areas with seasonal malaria transmission (Golassa et al. 2015).

Uncomplicated malaria can be produced by any Plasmodium species and will depend largely on the degree of prior exposure (Bartoloni and Zammarchi 2012). $P$. malariae, $P$. ovale curtisi, and $P$. ovale wallikeri have been considered responsible for mild infections. However, it is known that $P$. malariae can cause important clinical complications or remain as a chronic infection for long periods of time (Collins and Jeffery 2007).

Severe malaria occurs in non-immune subjects infected with $P$. falciparum yet the derived complications can be avoided with early diagnosis and appropriate treatment. Certain genetic disorders in the host like thalassemia (López et al. 2010) (Williams 2012) or sickle trait, the heterozygous state of normal hemoglobin $\mathrm{A}(\mathrm{HbA})$ and sickle hemoglobin $\mathrm{S}$ (HbS) (Cholera et al. 2008), can also protect against severe malaria. The severity and pathogenesis of the disease depend on certain surface proteins that are expressed by the parasite (Phillips et al. 2017), such as those encoding for var genes in P. falciparum (Wassmer et al. 2015) (Gillrie et al. 2016). Nowadays, there are more and more cases of severe malaria associated exclusively with P. vivax (Quispe et al. 2014). Patients from the Brazilian Amazon with severe $P$. vivax have suffered an increase in the expression of the genes involved in chloroquine resistance compared to patients with the mild form of the disease (Fernández-Becerra et al. 2009).

\section{Genetics in malaria diagnosis}

To determine the Plasmodium species, microscopy has been the main method employed worldwide. Two decades ago, rapid diagnostic tests were introduced and then improved upon over the years. These are of great use in remote areas that lack laboratory facilities but they only discriminate P. falciparum from the other Plasmodium species (such as $P$. vivax); they also provided only limited sensitivity for lowlevel parasitemias (Abba et al. 2014; Li et al. 2017). Their performance can further be affected by parasite polymorphism (Cheng et al. 2014) (Cheng et al. 2014). Moreover, to end malaria, one has to be able to accurately diagnose all malaria species affecting humans, including $P$. malariae, $P$. ovale curtisi, . ovale wallikeri, P. knowlesi, and other zoonotic 
variants. These results will also allow us to update their geographical distribution and to obtain epidemiological data.

In a symptomatic patient, the identification of $P$. falciparum is prioritized over the other species to prevent disease severity, especially in young children. It is known that uncomplicated P. falciparum can become severe within 24-48 days following diagnosis, even if the parasitemia is low. Moreover, it is common to find $P$. falciparum infections co-existing with other human malaria that are not considered fatal. To address this problem, the molecular tools now available can be far more accurate and sensitive in detecting low parasitic densities, mixed infections, treatment outcomes, and gametocyte loads. They can also be used to detect gene polymorphism involved in drug resistance or vaccine development (Tangpukdee et al. 2009; Britton et al. 2016) and for detecting other parasite characteristics that are useful for surveillance and to hasten malaria elimination.

Conventional molecular techniques (PCR assays) might not be sufficient because there is a cross-reaction effect between P. knowlesi and P. vivax (Sulistyaningsih et al. 2010). For this reason, mtCOI gene amplicons were analyzed to distinguish human cases of $P$. knowlesi in Indonesian patients (Setiadi et al. 2016).

The P. malariae and P. brasilianum genomes are very similar (Talundzic et al. 2017). In fact, the recent unexpected detection of $P$. malariae in Costa Rica could be due to $P$. brasilianum. By aligning the genomic sequences obtained, a 99\% accurate identification of P. malariae was achieved when isolated from atypical human cases occurring in Asia; and a $99 \%$ identification accuracy was also achieved for a $P$. brasilianum sequence isolated from a non-human primate in Guiana. In Costa Rica, P. brasilianum was earlier reported in monkeys (Chinchilla et al. 2006). In spite of this, there is no straightforward, complete diagnostic method to distinguish between both species with certainty. The detection of $P$. malariae subtypes and their close genetic relationship to $P$. brasilianum suggest that both species might correspond to a complex group (Talundzic et al. 2017; Rutledge et al. 2017).

Microscopic examination alone might be insufficient in diagnosing the Plasmodium species P. vivax and P. simium - in a recent study carried out in the Atlantic forest of Brazil, an attempt was made to differentiate these types of parasites infecting humans and monkeys, respectively (Brasil et al. 2017). The analysis of the mitochondrial genome revealed the close genetic relationship between the two species and confirmed the presence of $P$. simium in a large number of samples by means of two single nucleotide polymorphisms. Nevertheless, distinguishing one species from the other (P. vivax from $P$. simium) is no easy task. More recently, a single differential mutation from the mitDNA was used to develop a molecular test to distinguish between both species (de Alvarenga et al. 2018); this was made possible by analyzing a larger number of samples. However, it is necessary to monitor the method's performance and probably add new differential SNPs. In addition, the $P$. simium genome, as cited by Grigg and Snounou et al. (Grigg and Snounou 2017), together with further population studies, might uncover new genetic markers and their genetic relationship to the $P$. vivax parasite and its transmission dynamics.

The ultra-deep sequencing of genes $18 \mathrm{~S}$ rRNA, citb, and $c l p C$ proved useful in determining distinct species affecting humans in Gabon. Multiple genotypes from each species were determined, including those at low frequency, and even $P$. ovale curtisi mixed with $P$. ovale wallikeri were detected (Lalremruata et al. 2017).

The power of molecular tools has also been employed to distinguish $P$. cynomolgi from $P$. vivax in human infection (Snounou et al. 1993). P. cynomolgi and other non-human primate malarial parasites might be able to infect humans via mosquito bites more often than previously thought (Ta et al. 2014). In the forests of Vietnam, different non-human primate species were found to infect An. dirus, a mosquito that transmits human malarias (Maeno 2017). More genomic and genetic studies are needed on non-human primate parasites capable of infecting humans, which will hopefully assist in the development of reliable diagnostic tools and in understanding their dynamics and adaptation processes. However, would this be sufficient to end malarial transmission?

\section{Vaccines}

Searching for a vaccine against malaria continues to be the goal of many researchers today. There are various reasons why an effective vaccine against Plasmodium has not yet been developed-its complex life cycle and enormous antigenic variability, insufficient knowledge of the immune responses triggered by the parasite, and the lack of adequate animal experimentation models. In spite of all this, the natural immunity acquired by residents in malaria-endemic areas and the sterilizing immunity shown by volunteers exposed to irradiated sporozoites helps one to believe that developing a vaccine might be possible (Rieckmann et al. 1979; Hoffman et al. 2002; Roestenberg et al. 2011).

Most trials have focused on P. falciparum, as this is the species causing the most severe form of the disease. However, in recent years, $P$. vivax has also been studied because it is the most widespread species, and is even more serious than P. falciparum in some regions. Another reason is the frequent occurrence of mixed infections from both species in certain geographical areas (de Camargo et al. 2018).

Over the last few years, malarial epidemiology has undergone certain changes (Ceesay et al. 2008; O'Meara et al. 2008; Roca-Feltrer et al. 2010) - in 2013, the Malaria Vaccine Roadmap established new guidelines for the development of a vaccine (Moorthy et al. 2013). These stated that vaccines 
have to be effective against Plasmodium falciparum and Plasmodium vivax, and consider all malaria-endemic areas, not only sub-Saharan Africa. Immunization has to include all ages, not just children younger than 5 years of age. The objectives set for 2030 are the elimination of malaria in multiple places, demanding vaccines that are highly effective against the disease.

In 2011, the malERA (Alonso et al. 2011) introduced the term "vaccines that interrupt malarial transmission (VIMT)" including (i) anti-vector vaccines, directed at important molecules in the mosquito necessary for developing the parasite, (ii) pre-erythrocytic vaccines that act against sporozoites inoculated by the insect vector, thus preventing the invasion of the liver cells, (iii) erythrocytic vaccines acting against the merozoites, blocking the invasion of erythrocytes and reducing the number of blood forms, and (iv) vaccines directed at the sexual phases, known as altruistic vaccines; these do not prevent either the infection or the disease in the immunized person, but do prevent transmission to other people.

The VIMT concept is based on cycle bottlenecks, where the number of parasites is very low. This occurs firstly in the early exoerythrocytic phase when there is a low number of sporozoites inoculated by the vector, and secondly when gametocytes are ingested by the Anopheles females (Smith et al. 2014), where there is only a low presence circulating in human blood. Once the gametocytes pass to the mosquito's midgut, there is a significant reduction in their number until the formation of the oocysts - this could explain why, even in high transmission areas, most mosquitoes are not infected by the parasite. It is for this reason that gametocytes are a good target for developing vaccines that impede transmission. For a long time, however, there have been attempts to develop vaccines against the asexual erythrocytic forms because these are responsible for the disease symptoms. Nonetheless, trials have since shown that human factors act by limiting gametocyte infectivity and therefore this should be the first step in reducing parasite numbers in the mosquito (Smith et al. 2014).

Currently, multiple vaccines are being evaluated, in the preclinical or clinical phase (Tables of malaria vaccine projects globally http://www.who.int/immunization/research/ development/Rainbow_tables/en/), the main objective being to induce humoral and cellular CD4+ and CD8+ responses, since the role of $\mathrm{T}$ cell exhaustion during malaria is known, as well as the induction of memory $\mathrm{T}$ and $\mathrm{B}$ cells (Wykes et al. 2014). The results of Bergman et al. confirm the effector role of antibodies and $\mathrm{T}$ cells against parasites using the in vivo Imaging System (Bergmann-Leitner et al. 2014).

Pre-erythrocytic vaccines aim for a humoral and/or cellular response, inducing antibodies that prevent the sporozoites from invading the liver cells and/or acting on the infected hepatocytes. The immunological basis of the asexual bloodstage vaccines comes from more than 50 years of results on the passive immunity transmitted through the serum of immune adults to infected children, significantly reducing the number of parasites and the disease's clinical symptoms (Cohen et al. 1961). Many vaccines are being developed against different parasite proteins that target natural immunity using different technologies and formulations (Conway 2015). Subunit vaccines contain key specific antigens (one or a few) and can be constructed as recombinant proteins (soluble or forming virus-like particles), large synthetic peptides, recombinant plasmid DNA, or recombinant viral vectors. The results obtained with vaccines based on viral vectors in heterologous prime-boost regimens represent a hopeful way of inducing potent $\mathrm{T}$ cell responses (Venkatraman et al. 2017). It is also important to use appropriate adjuvants in the formulation of vaccines since these stimulate the immune response, whether humoral or cellular, increasing protection against infection and disease (Lee and Nguyen 2015; Sastry et al. 2017).

Advances in our understanding of host-parasite interactions (Acharya et al. 2017; Cowman et al. 2017) have allowed us to select key parasite development proteins and design possible vaccines that act on the asexual forms of the parasite: sporozoites in the hepatic or pre-erythrocytic phase, and merozoites in the erythrocytic phase. However, despite the 5507 genes contained in the P. falciparum genome, only 22 encode for proteins that are used in subunit vaccine development. The same antigens are sometimes used on different platforms, with different adjuvants, or in combination with other parasite antigens (Tuju et al. 2017). Today, multi-component/multi-stage/ multi-antigen vaccines are at an early stage of development. It is hoped that these "next-generation vaccines" will have highly effective presentations (Draper et al. 2015).

\section{Pre-erythrocytic vaccines}

One of the most important antigens on the sporozoite surface is the circumsporozoite protein (CSP), the major surface coat protein of the Plasmodium parasite (Coppi et al. 2011). It is expressed at the beginning of the parasite infection, in the sporozoite and in the early liver stages. CSP is related to adhesion and hepatocyte invasion.

Currently, the vaccine that is in the most advanced stage of development is the anti-sporozoite subunit vaccine, RTS, S/AS01B, marketed as Mosquirix and developed for about 30 years by GSK in collaboration with the Walter Reed Army Institute of Research (WRAIR). It is based on a recombinant protein which contains parts of the P. falciparum CSP combined with a surface antigen of the hepatitis B virus and a patented adjuvant (AS01), formed as virus-like particles without infective capacity (Wilby et al. 2012).

The final results obtained with this vaccine in phase 3 showed protection against the disease in children and infants for at least 3 years (D'Alessandro et al. 2015). In July 2015, the Committee for Medicinal Products for Human Use (CHMP) of the European Medicines Agency (EMA) adopted 
a positive scientific opinion regarding RTS, $\mathrm{S}$ for use outside the EU. In 2016, in a cost-effectiveness study using mathematical models, it was concluded that the use of this vaccine would represent a very favorable balance in an area with moderate to high infection transmission (Penny et al. 2016). In 2018, through the Malaria Vaccine Implementation Program (MVIP), the RTS, S vaccine will be tested on young children in selected areas of Ghana, Kenya, and Malawi. The limited efficacy achieved by the RTS, S vaccine as well as the high protection against malaria in humans achieved by immunization with radiation-attenuated Plasmodium falciparum sporozoites inoculated by mosquitoes, has led to the development of vaccines with complete sporozoites (Clyde et al. 1973; Hoffman et al. 2002). Living parasites induce antibodies against multiple antigens, and immunization with these vaccines elicits a strong humoral and cellular response. This type of vaccine is being developed by a US biotech company, Sanaria. They have several candidate vaccines in various stages of development: PfSPZ Vaccine with sporozoites attenuated by irradiation; PfSPZ-GA1 with sporozoites attenuated by knocking out a gene for two proteins; Pfb9 and Pfslarp, both essential for hepatic development (van Schaijk et al. 2014); and PfSPZ-CVac with attenuated sporozoites in vivo by concomitant administration of an antimalarial drug. In the latter case, Sanaria has developed a product called PfSPZ, which is equal to PfSPZ Vaccine but with non-attenuated sporozoites (Richie et al. 2015; Mordmüller et al. 2017). This American company, together with its collaborators, are currently working on aspects of manufacturing and delivery, administration and clinical development (Hoffman et al. 2015). PfSPZ Vaccine and PfSPZ-CVac have induced high-level protection in humans against controlled malarial infections, by mosquito bite or by intradermal injection, respectively.

It is very important to devote resources to finding new sporozoite proteins capable of producing high and adequate antibody responses so as to design vaccines that block hepatic infection by inhibiting the prior stages, from the point of mosquito inoculation to its entry into the hepatocyte. All these efforts have to be combined in an attempt to obtain a multistage vaccine (Sack et al. 2017).

Recent research has shown that antibodies present in the serum of subjects immunized with whole sporozoite vaccines and protected from CHMI recognized a large number of antigens, and in some cases developed protection against infection (Aguiar et al. 2015; Peng et al. 2016). Some have already been included in new vaccine projects and are now being tested.

\section{Blood-stage vaccines}

An alternative to pre-erythrocytic vaccines are blood-stage vaccines (Miura 2016). The natural immunity acquired against the disease is mediated by antibodies fighting the blood forms of the parasite. The proteins present in the merozoite are very numerous but not all induce immunological protection, and many merozoite antigens studied for use in possible vaccines are highly polymorphic, differentially expressed in populations or functionally redundant. All this contributes to the fact that the development of these types of vaccines is more delayed than those of the pre-erythrocytic class. Such vaccines should decrease merozoite and gametocyte populations by limiting infection and the clinical symptoms of the disease.

Surface merozoite proteins, as well as certain apical proteins involved in the invasion of the erythrocyte, have proven to be good targets for vaccine preparation (Richards et al. 2013). Understanding the molecular mechanisms involved in the sequential process of red blood cell invasion has allowed us to better comprehend the role played by certain proteins involved in erythrocyte adhesion and penetration along with their capacity for producing host antibodies that block the ligands required for the merozoite invasion of the erythrocytes (Weiss et al. 2015).

At present, eight surface proteins or apical organs (MSP1 (K1 allele), MSP2 (3D7 allele), MSP1, AMA1, MSP3, GLURP, SE36, and RESA) have been selected to participate in blood-stage vaccines; all are important in erythrocyte invasion. Due to the great genetic variability of these proteins, none have yet shown significant results in infection or disease control. None are still in phase 3 of development:

The MSP1 surface protein is the most abundant and forms a complex with other surface proteins; successful merozoite invasion of the host erythrocytes is dependent on this protein complex (Lin et al. 2016).

The K1-MSP1 Allele is currently included in the Combination $\mathrm{B}$ vaccine formulation along with the 3D7IMSP2 allele, another protein from the surface protein complex, and RESA (Ring-infected Erythrocyte Surface Antigen), a protein discharged by the parasite into the red blood cell membrane that contains the merozoites (Mills et al. 2007); this interacts with the spectrin network, decreasing the deformation of the red blood cells (such deformation is fundamental to parasite survival during the ring stage).

Another merozoite surface protein that participates in vaccine development is MSP3, whether on its own or combined with a protein in the GMZ2 vaccine. This is a recombinant protein vaccine, composed of two Plasmodium falciparum blood-phase antigens: glutamate-rich protein (GLURP), which is the target of cytophilic antibodies, and merozoite surface protein 3 (Hermsen et al. 2007). This is the first blood-stage malaria vaccine tested in humans that decreases the incidence of malaria in children (Sirima et al. 2016; Amoah et al. 2017).

The apical membrane antigen 1 (AMA1), which is highly polymorphic, has also been tested as a vaccine against malaria. The results were not good, and no significant protection against clinical malaria was found. However, it is still 
considered a good potential candidate in a multi-component malaria vaccine (Thera et al. 2011).

SE36 is a new recombinant molecule based on the serine 5 repeat antigen (SERA5); this might be a good immunogen for a potential vaccine (Horii et al. 2010).

New vaccines try to use several antigens from different parasitic-cycle phases. These are the multi-stage vaccines, such as NYVAC-PF7, a testing phase vaccine against multistage parasite antigens. This is an attenuated virus vaccine containing genes encoding for proteins in the preerythrocytic phase (CSP, SSP, and LSA1), the blood stage (MSP1, AMA1, and SERA), and the mosquito-stage (Pfs25).

In other vaccines, synthetic protein peptides related to the invasion process are used; these include EBA175 (Tolia et al. 2005), RH5 (Volz et al. 2016), and P27A, a synthetic protein peptide exported through the membrane of the parasitophorous vacuole in the trophozoite stage (Kulangara et al. 2012).

All of the above focus on P. falciparum studies. However, in recent years, interest in $P$. vivax has increased and more and more projects are dedicated to finding an effective vaccine against this parasite. In addition to the difficulties already mentioned for $P$. falciparum, others can be added for $P$. vivax. These include its capacity to cause hypnozoite relapse in the liver and the culture problems present in the laboratory. In contrast to $P$. falciparum, most $P$. vivax vaccines are still in the preclinical development stage (Mueller et al. 2015; Phillips et al. 2017).

Based on what is known about $P$. falciparum, various authors agree that a high-efficacy vaccine for $P$. vivax transmission blocking requires the combination of multiple antigens (Mueller et al. 2015; Tham et al. 2017).

\section{Current research into the mosquito stages}

Transmission blocking immunity (TBI) entails the induction of antibodies against the parasite's sexual stages (the gametocytes, gametes, zygote, and ookinete); these antibodies are capable of blocking parasite development in the mosquito's midgut. In the pre-genomic era (before the year 2000), several molecules were discovered using biochemical and immunological approaches, and great advances were achieved in TB vaccines. Some of those molecules are still considered important vaccine candidates.

Malaria parasites have a complex but vigorous life cycle; to interrupt this, a variety of approaches needs to be developed. In the mosquito vector, malaria parasites express multiple molecules that can be intervention targets. Nevertheless, more knowledge is required concerning vector-parasite interaction and how the mosquito species drives parasite evolution. There are more than 40 mosquito species that transmit human malaria; these include Old and New World species that diverged around 95 mya (Moreno et al. 2010). Sinka et al. (Sinka et al.
2012) have demonstrated that there is an important differential distribution of the main Anopheline species in the world. The parasite developing in the mosquito midgut expresses hundreds of molecules that participate in parasite growth and evade the mosquito's defense mechanisms. Parasite and vector populations might have adapted to different parasite strains and ecosystems (Eldering et al. 2017).

Genetic analysis has shown that Pvs25/28 (Chaurio et al. 2016) and Pvs47 (Molina-Cruz et al. 2015) are under selection and differentiation pressures; mitDNA is important for parasite development in the vector (Pacheco et al. 2017); and some mutations on the citb gene are responsible for the interruption of parasite development in the mosquito (Goodman et al. 2016) - this result is of significant importance, given that atovaquone resistance selects citb mutants, which are unable to be dispersed by vector transmission.

\section{Pre-fertilization stages}

At present, advances have been made on P. falciparum and a P. berghei mouse model that interacts with Anopheline species (Akinosoglou et al. 2015). More than 500 molecules participate in parasite development in the mosquito (Bennink et al. 2016).

About 90 gametocyte proteins have been detected in proteomic studies and many of these might induce TBI. Pfs230, a gametocyte surface protein involved in gamete function, is a large protein containing 3135 amino acids comprised of complex domains, repeating six-cysteine (6-Cys) motifs with abundant disulfide bonds, anchored to the membrane surface by GPI (Williamson et al. 1995; Gerloff et al. 2005; Arredondo et al. 2012). The N-amino terminal has been of interest as a TBV. Given that conformational epitopes are protective, one challenge has been to produce the proper folding for this protein. Antibodies expressed in the baculovirus system were able to reduce oocyst density in a dose-dependent manner and this inhibition increased when complement was added. The antibodies against this protein affected the formation of male gametes (Lee et al. 2017). Pfs48/45 (Carter et al. 1995; Van Dijk et al. 2001; Pradel 2007), another TBV that comprises protective conformational epitopes, tested in combination with Pfs25, both eliciting strong antibody responses (Datta et al. 2017). Pfs47 is expressed on the surface of female gametocytes and gametes (van Schaijk et al. 2006; Pradel 2007), and protects the parasite from a complement-like response mediated by TEP-1 and LRMI in the mosquito midgut through a selective processes; this shows high genetic structure (Molina-Cruz et al. 2013).

During the malaria season, antibodies against Pfs 230 and Pfs48/45, and against other proteins such as Pfmdv1, Pfs16, PF3D7 1346400, and PFeD7_1024800, increased in almost all sample subjects (Skinner et al. 2015). Because the low antibody response might not be boosted by natural exposure, a different approach is required by printing certain 
modifications for expression in the vector that are capable of inducing strong, long-lasting immunity.

P. vivax expressed the orthologs of the main TBV candidates, Pvs230 (Tachibana et al. 2012), Pvs48/45, and Pv47 (Tachibana et al. 2015). A locus associated with vector diversity was revealed that included Pvs47 (PVX_083240) and Pvx48/45 (PVX_083235). As previously found, there are continental-specific Pvs47 and Pvs48/45 SNPs (and haplotypes), consistent with the presence of different species of mosquito in each region; this resembles the pattern found in P. falciparum (Vallejo et al. 2016; Benavente et al. 2017b). However, it seems that the selective pressure on Pvs47 has been more recent than that on the ortholog of $P$. falciparum (Hupalo et al. 2016). Recently, a study of $P$. malariae 48/45 showed little polymorphism amongst isolates from Southeast Asia (Srisutham et al. 2018).

\section{Ookinetes and gliding motility}

More than 500 transcripts have been detected in P. falciparum gametocytes, and more than half of these are under translational repression; for example, P25/28. This gene is expressed in the ookinete while other genes have been found that express in the oocyst and/or the sporozoites, suggesting that transcribed genes are under variable-term storage. This is a strategy to accomplish sexual reproduction and differentiation expression in an efficient and timely manner (Lasonder et al. 2016).

The ookinete expresses multiple proteins during its formation in the blood meal and its migration through the midgut epithelium. The most abundant and conserved surface proteins amongst the P25 and P28 Plasmodium species are promising vaccine candidates. They are transcribed during the preookinete stages although their translation is maximal in the ookinete, as has been shown in P. falciparum (Saxena et al. 2007), P. vivax (Sattabongkot et al. 2003) and other malaria species. It has been suggested that P28 is ancestral to the duplicated P25 gene; antibodies against these proteins as well as knockout gene manipulation impede its development (Baton and Ranford-Cartwright 2005). First of all, two P28 types were detected in P. ovale (Tachibana et al. 2001), which were linked to a different variant of the rRNA type A gene (Tachibana et al. 2002). Genomic studies proved that these two types actually correspond to different species. In P. ovale wallikeri, P28 is encoded by four genes - one adjacent to P25, one $\mathrm{p} 28$ gene copy within an orphan contig, and two copies within contigs that contain a large array of oir genes (Ansari et al. 2016). P. ovale curtisi, on the other hand, has two P28 copies that have very low homology (Tachibana et al. 2001). It is not clear if gene expansion occurred in response to vector specificity. It is possible that the different Plasmodium species might have evolved differently or been under different selective pressures in the passage to humans and different vector species, selecting distinct genotypes at the local level, as observed in two P. vivax P25/28 phenotypes (González-Cerón et al. 2010).

Gliding motility and transcriptional regulation are mechanisms that allow successful parasite development in the mosquito. As with other invasive forms, the ookinete lacks rhoptries. The glideosome is a large group of proteins arranged in an actin-myosin motor. Proteins participate from the micronemes and the inner membrane, along with glideosome-associated proteins (GAP, e.g., GAP50, GALM2). The microneme proteome exposes hundreds of molecules (Lal et al. 2009). During the invasion process, these molecules are systematically secreted to the parasite surface (e.g., chitinase, von Willebrand Factor A domain-related protein (WARP), CTRP, SOAP, HSP70, CelTOS, PDI, A-M1 and others). There are other proteins that bind to the glideosome, one of these is Phil 1, which is integral to zoite development and is localized in the cytoskeleton and the apical end; its expression is upregulated in the gametes and zygote (Saini et al. 2017).

Ookinete proteins are not greatly exposed to the human immune response unless they are also expressed in the blood or hepatic stages. Because of this, their polymorphism is probably the result of mosquito selective pressure. The PfWARP micronemal protein expressed in the ookinete and oocyst, which comprises a von Willebrand factor A domain, has shown limited polymorphism (Richards et al. 2006); antibodies against WARP, CTRP and chitinase reduce $P$. falciparum 3D7 infectivity to Anopheles gambiae and An. stephensi ( $\mathrm{Li}$ et al. 2004). PfCelTOs, on the other hand, is expressed in ookinetes and sporozoites (Espinosa et al. 2017).

The PfCTRP (CSP, TRAP-related protein) is a member of the TRAP-MIC2 family. This family shares the same structure: they comprise a signal sequence, an $\mathrm{N}$-terminal domain, and at least one thrombospondin type 1 domain (TPS) whereas CTRP, TRAP and TLP have a von Willebrand type A domain (vWA), a transmembrane helix and a C-terminal tail. It has been proposed that the binding of the vWA domain causes an extension of the TSP domain (Moreira et al. 2008). CTRP is the most complex; it comprises six vWF domains and seven TPS domains. There is a single copy located in chr3 (Trottein et al. 1995). Disruption to PfCTRP allows ookinete development but affects ookinete gliding, also no oocyst develops (Templeton et al. 2000).

Another important protein in parasite invasion is Enolase, which is found on the surface of Plasmodium ookinetes. It promotes the invasion process, interacts with the midgut epithelium and captures plasminogen (Ghosh et al. 2011). Pf PPLP4, in the same family as MOAP, is an apical protein which presumably mediates ookinete traversal through the midgut epithelium (Wirth et al. 2015). In P. falciparum, antibodies against alanyl aminopeptidase (AnAPN1) were effective in reducing mosquito infection. 
Plasmepsin IV (known to be present in the asexual-stage food vacuole) was previously shown to be involved in Plasmodium gallinaceum infection in the mosquito midgut. Plasmepsins VII and X (not known to be present in the asexual-stage food vacuole) are upregulated in the Plasmodium falciparum mosquito stages ( $\mathrm{Li}$ et al. 2016). Many of these proteins are orthologous in $P$. vivax and other species; for example, PvCelTOS, PvChit, PvCTRP and PvSOAP.

\section{Sporozoite glideosome and its preparation for hepatocyte invasion}

At present, three sporozoite types have been detected based on their protein expression profile and confirmed by genome analysis - in the mosquito midgut, in the salivary gland and inside the vertebrate host.

Several proteins have been identified on the parasite surface; these include CSP, STARP, LSA-3, SALSA, SPART, PfEMP3 in the micronemes; and TRAP, SPECT1, SPECT2 and MAEBL in sporozoites (Garcia et al. 2006). CelTOS is a microneme protein in ookinetes and salivary gland sporozoites, which participates in parasite migration through the midgut epithelium and the sinusoidal cell layer. Although it is expressed in the midgut sporozoite and the merozoite, it is not translated until the sporozoite has invaded the salivary gland (Kariu et al. 2006). Pf CelTOS has low diversity, most of the non-synonymous variations are detected at the carboxyl end, most likely as a result of human immune pressure and intragenic recombination (Pirahmadi et al. 2018).

More recently, new molecules have been added to the list. These include the TRAP/MIC2 family, mostly micronemal proteins important for the ookinete and the sporozoite glideosome. Also, TRAP, aldolase, AMA1 and SPECT2 are essential for hepatocyte invasion (Buscaglia et al. 2004). AMA1 is expressed both in merozoites and in the liver stages (Yang et al. 2017). In sporozoites, CSP and microneme proteins such as TRAP are transcribed while in the skin or traveling to the liver. A comparison of transcriptomes and proteomes in gametocytes and sporozoites show that many transcripts are under translational repression and are expressed only at the particular time.

In sera taken from humans immunized with irradiated sporozoites, a range of new antigens has been detected in a high percentage of individual $(>50 \%)$, more than for CSP and TRAP antigens; for example, Ag2 was detected in $100 \%$ of immunized individuals. Some of these proteins have the dual function of invading both the salivary gland and the hepatocyte (e.g., CSP, TRAP, MAEBL). In the skin, before the sporozoite invades the hepatocyte, the molecular machinery needed to invade and develop in the hepatocyte is translated; this likely occurs in the irradiated sporozoite. In P. falciparum sporozoites incubated at $37 \mathrm{C}$ in the presence of hepatocytes, $>500$ genes were upregulated, while in rodent malaria, they were not found to be orthologous for about $25 \%$ of those genes (Siau et al. 2008). In the sporozoites, the expression of CSP, TRAP, AMA1, aldolase, SPECT2, CelTOS and PPLI did not change. Only two molecules that expressed in the human sporozoite were implicated in hepatocyte invasion (the sporozoite invasion-associated proteins SIAP-1 and SIAP-2 were detected on the parasite surface). It is interesting that SIAP-2 was only detected in primate malaria genomes (e.g., P. vivax and $P$. knowlesi) but not in rodent malaria, whereas SIAP-1 is present in all genomes. Likewise, LSAP1 and LSAP2 were exclusive to primate malaria (Siau et al. 2008).

The ApiAP2 family is comprised of 14 members, which have AP2-binding domains and participate in controlling the transcription of the life cycle. The functions of some of these have been studied recently. AP2-G2 is a repressor in both the asexual and sexual stages. Four AP2 (-0/-02/-03/-04) participate in transforming the zygote into the ookinete and oocyst. Other AP2s (SP/SP2) are required to form sporozoites but to be infective, AP2-SP3 is required (Modrzynska et al. 2017).

\section{Human malaria species}

In 2017, Rutledge et al. (Rutledge et al. 2017) established the phylogenetic relationships in human malaria constructing a maximum-likelihood tree using 1000 conserved single-copy core genes presents in the six species (Fig. 2). In addition to these six, about 200 different species of Plasmodium have been described parasitizing other mammals (other than humans), reptiles and birds. Taxonomically, Plasmodium is part of the family Plasmodiidae, of the order Haemosporida, the Class Aconoidasida and the Phylum Apicomplexa.

The use of more complex technology such as DNA arrays or massive sequencing has been fundamental in understanding the different mechanisms that the parasite uses; for example, to adapt to an environment, penetrate its host or escape from the action of certain drugs (Olszewski et al. 2009) (Doolan et al. 2014).

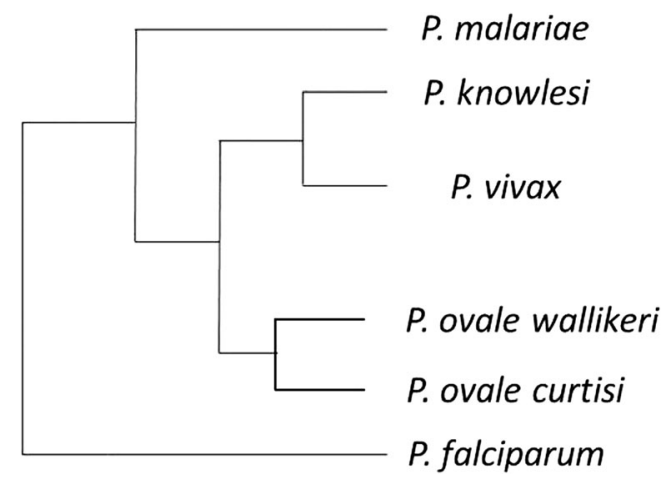

Fig. 2 Phylogenetic tree of the genus Plasmodium that causes human malaria 
These technologies provide knowledge regarding the parasite's persistence in different regions by deciphering what genomic changes favor its transmission. Some of the work being undertaken by the international scientific community focuses on identifying the genetic loci that might be associated with phenotypes related to drug resistance (RanfordCartwright and Mwangi 2012). Other work lines focus on the study of population genetics or genomics, with the intention of providing information on the spread of the disease and its origins (Hay et al. 2004). More knowledge of vectorparasite interactions will be useful in deciphering vector transmission. Understanding how the parasite is evolving in and across different ecosystems is a primary tool in definitively eliminating the disease.

The NGS methodologies are now being simplified considerably; this is providing scientists with a powerful tool that allows them to read DNA on a large scale, at an affordable price and over a short time (Garrido-Cardenas et al. 2017) this is even the case for blood infected with non-falciparum malaria at low parasitemia levels. Its main goal has been the identification of single nucleotide polymorphisms (SNPs), indels (insertions and deletions) and microsatellites in order to detect regions under selective evolutionary pressure, as well as to assist advances in system biology. The high throughput (HTP) application is also capable of describing polyclonality, and deep sequencing can detect the low-frequency genotypes.

Thanks to DNA sequencing, the $P$. falciparum genome was sequenced in 2002 (Gardner et al. 2002). Subsequently, the genomes of P. vivax (Carlton 2003) and P. knowlesi (Pain et al. 2008) were sequenced during the first decade of the twenty-first century. More recently, the genomes of $P$. malariae (Ansari et al. 2016; Rutledge et al. 2017), P. ovale wallikeri and P. ovale curtisi (Ansari et al. 2016) were sequenced, completing the six genomes of human malarial species. Other non-human primate Plasmodium species, capable of infecting humans by accident, or by a mosquito bite, are being targeted for genomic studies. The first draft of the $P$. brasillianum genome is in the process of being published (Talundzic et al. 2017). Consequently, using comparative and functional genomics, we might gain a full understanding of parasite biology - its evolution, vector adaptation and pathology, amongst other things.

Additionally, the development of functional genomic, proteomic, metabolomic and transcriptomic analyses are contributing a great deal of information regarding the basic molecular function of the parasite (Tymoshenko et al. 2013). Although the identification of genes associated to drug resistance is a priority, identifying genes associated with phenotypes related to clinical manifestations of high pathogenicity may become critical in disease control. On the other hand, the analysis of different Plasmodium species populations might help in the parasite's molecular barcoding, necessary for epidemiological surveillance. In fact, the variability in malarial epidemiology worldwide requires multiple methods and approaches.

\section{Plasmodium falciparum}

P. falciparum causes the most severe disease in humans. This species has been studied for decades because of its high parasitemia and ability to grow in vitro. Genomic data are continually being gathered from different laboratory strains and field isolates. At present, there are 36 different genome assemblies. The comparative analysis of these genomes aims to understand the evolutionary aspects of $P$. falciparum, theoretically related to its biology, pathogenicity and drug resistance. Likewise, it is hoped information is found that allows us to understand certain mechanisms such as its medicine resistance, transmissibility and immune evasion.

The Plasmodium falciparum genome was first published by Gardner et al. in 2002 from the 3D7 strain; this was as a result of the work carried out by the P. falciparum Genome Sequencing Consortium, established in 1996. The nuclear genome of $P$. falciparum 3D7 is organized into 14 linear chromosomes plus two circular fragments of extra-chromosomal DNA, one apicoplast and one mitochondrial genome. This genome is publically available through geneDB or plasmoDB, the main databases for Plasmodium. The nuclear genome has a size of $23.3 \mathrm{Mb}$, a GC content of approximately $19.4 \%$, and 5507 genes (Table 1). Most genes are between 2000 and $2500 \mathrm{bp}$ in length and they do not contain introns, or at least there are very few. Most families of hypervariable and highly amplified genes are found in the subtelomeric regions of the chromosome; in the central region of this, protected against instability, are the genes related to the parasite's metabolic functions (Rovira-Graells et al. 2012). The subtelomeric chromosomal regions in the $P$. falciparum genome are very dynamic in evolutionary terms. The size of this region ranges from 60 to $120 \mathrm{~kb}$ and has a well-studied structure, with 1 to 6 telomereassociated repeat elements and several virulence genes and surface antigens which play critical roles in virulence, immune evasion and antigenic variation (de Bruin et al. 1994). The $P$. falciparum mitochondrial genome is only $6 \mathrm{~Kb}$ in size (Vaidya et al. 1989), and most of its DNA consists of shortsequence tandem repeats. It has only three genes that encode for the proteins Cox $1, \operatorname{Cox} 3$ (subunits 1 and 3 of cytochrome c oxidase) and Cytb (cytochrome b) (Hikosaka et al. 2011). An important feature of the mitochondrial genome is that it does not encode for any tRNA so this must be exported from the cytosol. The apicoplast genome is circular, $35 \mathrm{~kb}$ in size, and encodes for 30 proteins involved in essential pathways such as fatty acid or isoprenoid synthesis, as well as in the heme group pathway (Foth and McFadden 2003).

The $P$. falciparum $3 \mathrm{D} 7$ genome is being continually revised and reannotated. It has been used as a reference in numerous trials, such as that carried out by Chang et al. in 2013 (Chang et al. 2013), where they analyzed the data obtained from the complete genome sequencing of the 159 P. falciparum strain from Senegal. There was high variation in the single 
Table 1 Features of the nuclear genomic assemblies in parasites that cause human malaria

\begin{tabular}{|c|c|c|c|c|c|c|}
\hline Feature & P. falciparum & P. vivax & P. knowlesi & P. ovale curtisi & P. ovale wallikeri & P. malariae \\
\hline Reference strain & 3D7 & PvP01 & H Pk1 (A) & a & $\mathrm{b}$ & c \\
\hline Present in GeneDB & Yes & Yes & Yes & Yes & No & Yes \\
\hline Present in PlasmoDB & Yes & Yes & Yes & Yes & No & Yes \\
\hline Genome size $(\mathrm{Mb})$ & 23.3 & 29.0 & 23.5 & 33.5 & 33.5 & 33.6 \\
\hline GC content & 19.4 & 39.8 & 37.5 & 29 & 29 & 24 \\
\hline Gene number* & 5507 & 6642 & 5188 & 7132 & 7052 & 6540 \\
\hline$p i r^{*^{2}}$ & 227 & 1212 & 68 & 1949 & 1375 & 255 \\
\hline var & 60 & 0 & 0 & 0 & 0 & 0 \\
\hline SICAvar & 0 & 0 & 136 & 0 & 0 & 0 \\
\hline phist & 81 & 82 & 44 & 54 & 21 & 30 \\
\hline fam-m & 0 & 0 & 0 & 0 & 0 & 283 \\
\hline fam-l & 0 & 0 & 0 & 0 & 0 & 396 \\
\hline surfin & 10 & 2 & 0 & 80 & 141 & 129 \\
\hline
\end{tabular}

*Including pseudogenes and partial genes, excluding non-coding RNA genes

$*^{2}$ Also vir/kir/oir/mir

${ }^{\text {a }}$ One isolate was from a Chinese worker returning from West Africa and the other corresponding to the CDC/Nigeria I strain

${ }^{\mathrm{b}}$ Isolates obtained from two Chinese workers returning from West Africa

${ }^{\mathrm{c}}$ Isolates obtained from travelers returning to Australia from Africa

nucleotides and the number of copies, indicating that the parasite is subjected to significant selective pressure.

A study of the genome of 65 Gambian P. falciparum isolates showed, as expected, a high level of polyclonal infections (57\%) and balancing selection signatures in genes encoding for antigenic molecules; the strongest signal was on the mps3-like gene belonging to a family with a role in immune evasion. In each schizont, a different gene type was found to be expressed. This, along with other blood-stage antigens, including one hypothetical protein, demonstrated the highest level of polymorphism, with a Tajima value above 1.0. Such a result is exceptional, as most genes have negative Tajima values reflecting their historical population expansion and purifying selection (Amambua-Ngwa et al. 2012).

Understanding this variability will make it easier for scientists to determine the population structure of these parasites. Different studies have shown that genes related to diverse metabolic pathways, as well as genes related to protein degradation, are under directional selection. The genes, or gene families, that are of greatest interest in definitively eradicating malaria, and thus the most studied, are those related to immune evasion mechanisms and drug resistance.

Establishing gene families is a very useful strategy for several reasons, the main one being that, in genomic studies, this allows us to know the evolution over time of the gene functions (Ohta 2000). Another important advantage is that it is easier to predict its function once we have assigned a gene to a gene family. In general, genes of the same family have similar functions. From this, we can study the most important gene families in P. falciparum to fight the disease.

\section{The pir gene family}

The Plasmodium interspersed repeats (pir) multi-gene family is related to immune evasion and encodes several variant surface antigens (VSAs) (Janssen et al. 2004). The P. falciparum genes belonging to this family are known as rif (repetitive interspersed fragment) and stevor (subtelomeric open reading frame) genes. At present, rif and stevor gene families are treated as a single family because the proteins they encode for, STEVOR and RIFINS, are identical from a probabilistic model perspective. This is reflected in the Pfam model for the two protein families, presented by Bateman and Lawson (accession number PF02009).

The action mechanism of the rif/stevor gene family is by recognizing Glycophorin $\mathrm{C}$ receptor on the red blood cell (Niang et al. 2014), making it possible to chronicle an infection by means of an adaptive immunity mechanism controlling antigenic variation. Most of the pir genes described so far have a common structure, consisting of two or three exons, the last of which encodes for a transmembrane domain (Janssen et al. 2002).

In mice models, only a small percentage of the parasites in an acute blood infection expressed pir genes, while almost all parasites express them in a chronic disease (Brugat et al. 2017). This mechanism, mediated by pir genes, facilitates the transmission of the parasite reservoir to other human hosts.

However, although evasion mechanisms are understood to be the primary function of pir genes, analyses carried out on Plasmodium chabaudi, a parasite infecting mice, suggests that the proteins encoded by these genes might have other 
functions in a blood-stage infection, such as interaction with host molecules. It is also possible that they play an important role in signaling, traffic and cell-adhesion mechanisms (Yam et al. 2016).

\section{The var gene family}

This gene family encodes for highly polymorphic proteins called PfEMP1 (Plasmodium falciparum erythrocyte membrane protein 1), also related to the process of antigenic variation. These PfEMP1 proteins are what the parasite uses in its interaction with the human host (Flick and Chen 2004).

The 3D7-strain genome contains 60 var genes, distributed across almost all the chromosomes. Proteins encoded by var genes are expressed on the surface of the infected erythrocytes, where they interact with different human endothelial receptors, thus preventing the elimination of the parasite (Chen et al. 1998). Each parasite expresses only one var gene at a time, in a phenomenon known as allelic exclusion; this means that the remaining genes present in the genome are transcriptionally silenced, waiting for the immune system to develop a response to the expressed protein, at which point they change the expression and restore their infective capacity (Voss et al. 2005).

Var genes can be divided into three families, depending on their location on the chromosome (Lavstsen et al. 2003). Group A genes are found in subtelomeric regions, those of group $\mathrm{B}$ are scattered in the chromosome, and group $\mathrm{C}$ are only present in regions interior to the others. Regardless of their location, all the genes in this family share a gene structure consisting of two exons separated by a small well-conserved intron. The first of the exons has a series of characteristic domains: an N-terminal segment (NTS), plus several Duffybinding-like (DBL) and cysteine-rich interdomain region (CIDR) domains. The second exon codes for the intracellular component of PfEMP1. Comparing different $P$. falciparum whole-genome sequencings has identified dozens of structural variations, duplications, deletions, translocations and single nucleotide polymorphisms (SNPs) associated to var (Claessens et al. 2014). All these genetic variations give rise to the extensive polymorphisms found in PfEMP1 proteins. There are two promoters for each gene. One is upstream of the open reading frame responsible for mRNA production, and the other is included in the intron, promoting the production of sterile non-coding transcripts.

\section{The PHIST gene family}

Eighty-nine members of this highly amplified PHIST (Plasmodium helical interspersed subtelomeric) gene family have been predicted (Sargeant et al. 2006). These proteins have a similar number of amino acids, about 150 , which have a significant presence of highly conserved aromatic residues in an alpha-helical structure (Warncke et al. 2016). All share a uniform pattern of exportation to the erythrocyte cytoplasm due to the presence of a PEXEL (Plasmodium export element) or HT motif, consisting of a pentameric amino acid motif $\mathrm{RxLxE} / \mathrm{Q} / \mathrm{D}$, which directs the protein's localization.

PHIST proteins carry out different functions related to the remodeling of the erythrocyte structure during the asexual cycle; this facilitates the parasite's survival and multiplication as well as its immune system evasion - in this way, the erythrocyte becomes a suitable host cell (Moreira et al. 2016). PHIST proteins are also involved in very important metabolic processes such as the visualization of the PfEMP1 surface, gametocytogenesis and changes in cell stiffness (Zhang et al. 2017).

Currently, PHIST proteins are classified into three subfamilies, which differ both in their sequence and in their function. The PHISTa subgroup consists of 26 very short proteins, present exclusively in P. falciparum. They have two characteristic conserved tryptophan residues. The family members are transcriptionally silenced in strain 3D7 (Scholz and Fraunholz 2008). The PHISTb subfamily consists of 24 members. Its primary structure is significantly longer than that of other PHIST proteins since it has a stretch in the C-terminal, of unknown function. It is thought that the function of these proteins is related to the remodeling of the iRBC (infected red blood cell) cytoskeleton, contributing to the malaria pathology (Tarr et al. 2014). PHISTc is the best known subgroup, consisting of 18 proteins entirely shared with $P$. vivax and $P$. knowlesi; it seems that their function is related to protein trafficking (de Koning-Ward et al. 2009).

It is expected that, given the role PHIST proteins play in the remodeling of the host, these are very important in processes such as gametocytogenesis or in different mosquito stages; however, at the moment, this knowledge is not available.

\section{Artemisinin-resistance genes: kelch13}

Genome studies have discovered that single point mutations in the kelch13 gene were associated with slow-elimination parasite clearance (RCA) in malaria patients treated with artemisinin-based combination therapy (ACT). The mutation mapped onto the $\beta$-propeller and BTB/POZ domains of the encoded kelch-like protein (PF3D7_1343700, on chromosome 13) (Cheeseman et al. 2012; Ariey et al. 2014). This can become a very serious problem in the fight against malaria since artemisinin and its derivatives are currently the most powerful drugs used against the disease (Burrows 2015). These drugs were introduced at the end of the twentieth century to treat parasites resistant to chloroquine or other drugs, and they reduced both malarial mortality and morbidity. However, artemisinin resistance in P. falciparum has recently been discovered (Mbengue et al. 2015). 
At least 20 kelch13 mutations have been identified that are associated with a slow parasite clearance rate following treatment with artemisinin derivatives; these affect the encoded propeller of the kelch13 protein (Miotto et al. 2015). The majority of SNPs, whether they are high or low frequency, are associated with a similar prolongation of the parasite clearance half-life. Most mutations appear from amino acid 440 onwards, and the most widespread is C580Y, which emerged independently in several distinct geographic locations (Ashley et al. 2014). The association of this and other mutations with slow clearance was validated in vitro and/or in vivo. Therefore, parasite monitoring is necessary to warn of artemisinin efficacy decay below 90\% (WHO 2016).

What draws our attention to these mutations is their geographic location. While forms of artemisinin resistance associated with kelch13 mutations have appeared in Vietnam, Thailand, Cambodia and Myanmar, they rarely do so in other Southeast Asian countries such as Laos or Bangladesh, nor do they in African countries. It has also been observed that there are background markers that seem to predispose the appearance of kelch13 mutations, the presence of which seems to be predominant in only some Southeast Asian countries. These background markers include arps 10 and $m d r 2$ on chromosome $14, f d$ on chromosome 13 , and crt on chromosome 7 (Miotto et al. 2015). It is assumed that each background marker acts differently although their significance is not known exactly. What is clear is that these mutations appeared earlier than those of kelch13.

\section{Other genes: crt, mdr, dhfr, dhps, and CAs}

These genes play an important role in mechanisms related to resistance to different drugs, molecule biosynthesis and others.

Pfcrt (chloroquine-resistance transporter) This gene is located on chromosome 7 and is related to chloroquine resistance in P. falciparum (Roepe 2009). The protein encoded by the Pfcrt gene is an integral membrane protein, with 10 transmembrane domains, present in the parasite's acid digestive vacuole; its function is unclear (Martin et al. 2009). Mutations at residue Lys76Thr result in reduced chloroquine accumulation by the parasite. The Lys76Thr mutation causes a loss of positive charge, changing the protein's substrate specificity to allow the transport of the protonated drug via the vacuole to a place far from its action site (Martin et al. 2009).

Recent studies conducted in Zambia (Mwanza et al. 2016) have shown that, after discontinuing the use of chloroquine as an antimalarial drug, the mutation was no longer detected; that is to say, when the pharmacological pressure was eliminated, the drug resistance disappeared, reestablishing chloroquine's great clinical efficacy.
Pfmdr1 (multi-drug resistance) This gene is located on chromosome 5 and it encodes for the P-glycoprotein homolog protein (PGH1), expressed throughout the parasite's asexual erythrocytic life cycle (Cowman et al. 1991). PGH1 is homologous to human P-glycoprotein, which intervenes in the pharmacological resistance processes in cancer cells. The Pfmdr1 gene is related to chloroquine resistance and also resistance to other drugs such as mefloquine and halofantrine (Sidhu et al. 2006). The first analyses carried out studying the Pfmdrl gene concluded that the parasite's resistance to different drugs was directly related to an increase in the number of copies of this gene (Price et al. 2004). However, later on it was realized this was not simply a numerical issue. Different haplotypes demonstrate different sensitivities to the use of antibiotics. Some haplotypes confer greater resistance to a certain drug than others, for an identical number of copies. Malmberg et al. (Malmberg et al. 2013) showed that parasites presenting the Pfmdr1 N86/184F/D1246 haplotype persist at higher lumefantrine concentrations in the blood than those expressing the mdr1 $86 \mathrm{Y} / \mathrm{Y} 184 / 1246 \mathrm{Y}$ haplotype. This means that resistance to different drugs, mediated by the Pfmdrl gene, is a parasite-strain-dependent phenomenon.

Pfdhfr (dihydrofolate reductase) and $P f d h p s$ (dihydropteroate synthetase) These genes are located on chromosome 4 , and chromosome 8 , respectively. Point mutations in these genes are implicated in the main mechanism of high-level sulfadoxine-pyrimethamine (SP) resistance (Wang et al. 1997). SP is an inhibitor of the folic acid pathway in $P$. falciparum; unfortunately, however, this drug's effectiveness in malaria treatment is decreasing due to the continuous emergence of resistance events. The Pfdhfr gene encodes for a protein containing 608 amino acids and $71.7 \mathrm{KDa}$, with an A + T content of 75\%; it has no introns (Bzik et al. 1987). In P. falciparum, the DHFR protein appears bound to a TS protein (thymidylate synthase) containing 94 amino acids, giving rise to the PfDHFR-TS bifunctional complex. The DHFR protein catalyzes the conversion of dihydrofolate to tetrahydrofolate, a cofactor used in the biosynthesis of certain amino acids and purine nucleotides (Peterson et al. 1988). The Pfdhps gene encodes for a DHPS protein that also appears biologically as a bifunctional complex, joined to a PPPK protein (dihydro-6-hydroxymethylpterin pyrophosphokinase). The gene has $2118 \mathrm{bp}$ encoding at the $83 \mathrm{KDa}$ protein, which contains 706 amino acids (Triglia and Cowman 1994).

Point mutations have been reported in different dhfr codons, which potentiate pyrimethamine resistance when acting synergistically (McCollum et al. 2008). These mutations are N51I, C59R, S108N, and I164L (Plowe et al. 1998). Similarly, mutations have been described in dhps at the S436A, A437G, K540E, A581G, and A613S codons, acting synergistically to enhance sulfadoxine resistance (Gregson and Plowe 2005). 
Pfcas (carbonic anhydrases) This is a gene that encodes for CA metalloenzymes. Different members of each of the five families described for this enzyme are present in all the life kingdoms (Alterio et al. 2012). The reaction carried out by the CA protein is the hydration of carbon dioxide to generate bicarbonate, which releases a proton. This generated bicarbonate will later be used in the de novo biosynthesis of pyrimidines. P. falciparum has two classes of Pfcas genes. One belongs to the so-called $\alpha$-class and encodes for a protein containing 235 amino acids (Krungkrai and Krungkrai 2011), while the other, recently described, belongs to the $\eta$ class and encodes for a protein containing 358 amino acids (Del Prete et al. 2014). The amino acid sequence analysis of the CA enzyme in P. falciparum revealed that it is different from the analogous protozoan and human enzyme sequences, and that the protein has different catalytic properties from the human variant. Given the essential metabolic role of CA protein in P. falciparum, different aromatic sulfonamides, which have been found to be efficient inhibitors of the enzyme, are being investigated as antimalarial drugs (Krungkrai et al. 2008); these limit P. falciparum gametocyte development.

In 100 P. falciparum clinical isolates from Guinea, 99,305 SNPs were detected; however, most of them (68\%) were exclusive to one isolate. When compared to the Gambian parasites, evidence was detected of recent positive and balancing selection; this was probably due to antimalarial drugs and host immunity. Only in the Guinean parasites were selective sweeps around $P f c r t$ and $P f m d r 1$ genes consistent with chloroquine usage. Even though selection signatures around the Pfdhps gene were only detected in the Gambian parasites, they were also consistent with the use of SP as a first-line treatment (Mobegi et al. 2014).

Recently, P. falciparum genome-wide SNP variation was studied in parasites selected in vitro for potential antimalarial compounds or "resistomes." In 262 parasites, 159 gene amplifications were detected along with 148 non-synonymous nucleotide changes in 83 genes. Pfmdrl mutations were associated with resistance to six different compounds (Cowell et al. 2018) (Cowel et al. 2018).

\section{Plasmodium vivax}

The main problem limiting our understanding of the biological parameters of the $P$. vivax parasite is the inherent difficulty of cultivating it in the laboratory and its low parasitemia. Studies of its genome are presented as an alternative to developing tools that allow therapeutic and epidemiological approaches. The Salvador I strain was the one used for the first complete $P$. vivax genome sequencing project (Carlton et al. 2008). This remains inaccurate due to the existence of a large number of unassembled scaffolds and the limited number of annotated genes. Genome drafts of other strains such as Brazil-I, India-VII, North Korea and Mauritania-I have also been used to gather useful data on the $P$. vivax genome. Recently, a new $P$. vivax sequence, PvP01 from a PNG isolate, has been assembled and annotated. Because of its superior quality, it can be used as a reference (212 coverage) (Auburn et al. 2016). The principle difference observed between the two analyses is the genome size. While the estimated size sequenced for the Salvador I strain is 26.8 megabases $(\mathrm{Mb})$, the assembly is larger for PvP01, at $29 \mathrm{Mb}$. This difference is mainly due to better assembly in the subtelomeric sequences. In fact, of the $26.8 \mathrm{Mb}$ sequenced in Salvador I, 4.3 Mb of small subtelomeric contigs were unassigned due to their repetitive nature (Carlton et al. 2008). In addition, thanks to the sequencing of the PvP01 strain, the complete sequence of the mitochondrial genome $(5 \mathrm{~Kb})$ and a partial sequence of the apicoplast genome $(29.6 \mathrm{~Kb})$ are also available. A second difference is observed in the number of genes found. While 5433 genes were identified in Salvador I, in PvP01 there were 6642 genes. This difference is mainly due to the genes belonging to subtelomeric-region families. In addition, the number of genes to which a function can be attributed has also increased, thanks to better assembly. On the other hand, the GC content in the Salvador I and PvP01 analyses is of a similar order (42.3 and 39.8, respectively); this is much higher than the $19.4 \%$ observed for $P$. falciparum.

As in the case of $P$. falciparum, several gene families can be found in the P. vivax genome. The analysis and knowledge of these can lead to the development of applicable tools for therapeutic studies.

\section{The vir gene family}

The genes in this family are variant surface antigen (VSA) expression genes. These are a homologous family to the pir gene family of $P$. falciparum, which comprise (along with the kir in P. knowlesi and the cir/bir and yir family in three rodent malarias) the main multi-gene family in malaria parasites. In $P$. vivax, these genes are related to the expression of certain cytoadherence proteins on the ICAM-1 endothelial receptor (Bernabeu et al. 2012), and also involved in antigenic variation (Fernandez-Becerra et al. 2009). However, in most cases, the function of this gene family is unclear, and the different members of the gene family can present different functions. In the Salvador I strain, 346 vir genes were found, which were grouped into 12 families named with the letters A-L. Analysis of the PvP01 strain has revealed the presence of more than 1200 genes in this family. The vir genes present multiple variants, with genes containing a single exon to genes with up to 5 exons, varying in size from 150 to more than $2000 \mathrm{bp}$.

As more isolates are sequenced, new information regarding parasite evolution emerges; e.g., the genomic analysis of an isolate from China-Myanmar (CMB-1), which revealed 78 novel vir genes. It has also been proposed that, in distinct 
samples, the gene families might cluster differently due to their rapid evolution (Chen et al. 2017).

\section{Other genes}

The P. vivax genomic analysis of global parasites showed that the most diverse antigenic genes are the merozoite surface proteins, (msp) 7 and 3, along with the serine repeat antigen (SERA) families (Hupalo et al. 2016). The CMB-1 strain showed high levels of genetic variability in genes belonging to the RBP, SERA, vir, MSP3 and AP2 families (Chen et al. 2017).

When comparing the $P$. falciparum and $P$. vivax genomes, about 4465 genes were found with sequence homology (Auburn et al. 2016). This is the case for the ortholog genes $p v-p h i s t, p v-c r t, p v-m d r, p v-d h p s$ and $p v-d h f r$. The functions of these genes are not yet clear in $P$. vivax. In fact, there is not even any conclusive evidence of the presence of polymorphism or their resistance to antimalarial drugs (chloroquine with Pvcrt/ $P v m d r$ and sulfadoxine-pyrimethamine with $P v d h p s / P v d h f r)$, as there is in P. falciparum. Indeed, there is hardly any molecular baseline epidemiologic data (Huang et al. 2014).

At first, it was proposed that mutations at $P v m d r l$ were associated with CQ resistance (Reed et al. 2000) but no association was detected with clinical outcomes in patients (Sá et al. 2005; Barnadas et al. 2008). Accordingly, the genome analysis exposed no signs of positive selection in these genes and no selective sweep was observed around the Pvmdr1 locus in Colombia or in other parts of the world (Hupalo et al. 2016). This gene seems to be a marker of parasite adaptation to local conditions similar to other genes involved in red blood cell invasion and drug resistance (Hupalo et al. 2016).

A distinct scenario has been shown in SP resistance. Polymorphisms at PvDHFR 57L, 58R, 117T/N and 173F have been associated with resistance to pyrimethamine (PM) in vitro (Hastings et al. 2005). These polymorphisms might be present at distinct frequencies in different geographic regions when using SP treatment for P. falciparum infections (Asih et al. 2015).

Genomic studies showed that in Colombian parasites, there is high diversity (33,853 SNPs; $42.7 \%$ of which were present in just one sample) (Winter et al. 2015); this is similar to parasites from other sites (Benavente et al. 2017b). A genetic sweep around Pvdhps was detected and the A383G amino acid substitution was present. $P v d h f r$ variation at the S58R and S117N residues has also been detected (Winter et al. 2015).

Furthermore, genomic analysis showed that selection intensity on chromosomes 5 and 14 (containing $p v d h f r$ and pvdhps genes, respectively) was stronger in parasites from western Thailand than those from western Cambodia and Papua, Indonesia. Chr10 and Chr14 regions had a selection signal comprised of unknown proteins (Pearson et al. 2016). Hupalo et al. 2016 also demonstrated the presence of a selective sweep in loci comprising the $P v d h p s$ and $P v d h f r$ genes.
Hypnozoites are a particular feature. To date, primaquine is the only drug licensed to eliminate them. However, even the most effective treatment scheme is accomplishing little, PQ tolerance has been reported and the maximal dose has reached a plateau in some regions due to G6PDH deficiency (Baird 2015). Discovering the factors that determine dormancy and their commitment is important for drug discovery. By cultivating $P$. cynomolgi (a non-human primate species that causes relapse episodes) in monkey hepatocytes, it was possible to employ NGS to obtain the transcriptome of small parasite forms, most likely hypnozoites or early liver stages. From the comparative genomics of the up and downregulating genes, 12 were not detected in the P. falciparum genome while 11 were present in $P$. vivax and $P$. ovale; the other one was specific to $P$. cynomolgi. The ApiAP2 family is involved in stage transaction; one of its members is PCYB_102390, the ortholog of which is present only in $P$. vivax and $P$. ovale. It was given the name AP2-Q and is probably involved in hypnozoite commitment. Other molecules that can contribute to quiescence and hypnozoite homeostasis might also participate in translational repression and post-transcriptional gene regulation (Cubi et al. 2017). Further functional studies are necessary to elucidate if these molecules could be the targets for new anti-hypnozoite drugs. Such results also highlight the importance of NGS technologies in studying other nonhuman primate malarias, making the genomes of many malaria species available.

\section{Plasmodium knowlesi}

Malaria produced by Plasmodium knowlesi in long-tailed Macaca fascicularis (Mf) and pig-tailed M. nemestrina (Mn) in Southeast Asia has been known about for quite some time. However, in 2004, several cases of human malaria were reported that were caused by the same parasite (Singh et al. 2004b). It is now known that $P$. knowlesi infections are widespread in humans in a large part of Southeast Asia (Kantele and Jokiranta 2011). Various genetic analyses have indicated that no systematic differences exist between the macaque and human isolates. On the other hand, mitochondrial DNA analysis reveals that $P$. knowlesi derives from an ancestral parasite that predates the settlement of Homo sapiens in Southeast Asia and, therefore, it had to be specific to monkeys. Hence, evolutionary analyses indicate that $P$. knowlesi is zoonotic. This is corroborated by the fact that the number of parasite genotypes is much higher in monkeys than in humans (Lee et al. 2011).

Phylogenetically, $P$. knowlesi is closely related to $P$. vivax, although at the phenotypic level there are important differences such as the absence of hypnozoites and, consequently, in $P$. knowlesi there is a latent hepatic stage. The P. knowlesi nuclear genome sequence was published in 2008 (Pain et al. 2008), coming from the $\mathrm{H}$ strain, $\mathrm{Pk} 1$ (A1) clone; its size is 
23.5 $\mathrm{Mb}$ and it presents extremely high genetic diversity. This polymorphism level is much higher than that in the $P$. falciparum and $P$. vivax genomes, and is of a similar order to that between human and macaque $P$. knowlesi. The genome has a GC percentage of $37.5 \%$, and 5188 protein-encoding genes. Approximately $80 \%$ of these genes are orthologous to genes identified in both $P$. falciparum and $P$. vivax although there are two large specific gene families, called SICAvar (schizont-infected cell agglutination variant) and Kir (knowlesi interspersed repeat). A distinctive feature of these variant antigen genes is that they are widely dispersed throughout the genome. Additionally, five families of genes unique to $P$. knowlesi, referred to as Pkfam-a to Pkfam-e, were described, each with 4-15 paralog members. The function of these families' genes is unknown although it has been suggested that some may be related to the export of proteins. Recently, a new reference genome was sequenced by combining PacBio (Pacific Biosciences Inc., USA), RS-II long read and Illumina HiSeq short read sequence data. The new obtained genome had a genome length of $24.4 \mathrm{Mb}$ and described the distribution of methylated bases (Benavente et al. 2017a).

At the genomic level, there are three highly divergent P. knowlesi subpopulations. Two of these appeared as a result of sympatric speciation in humans residing in Malaysian Borneo, probably because they were transmitted by different vectors. The third subpopulation was found in some laboratory isolates from other parts of Southeast Asia (Assefa et al. 2015).

\section{The kir gene family (similar to rifin/stevor in P. falciparum)}

This family of genes is responsible for the expression of variant surface antigens on parasitized red blood cells, and mediates cytoadherence processes along with genes from other gene families such as pir in P. falciparum and vir in P. vivax. Gene families with similar characteristics also exist in rodent parasites, such as yir in P. yoelii (Fonager et al. 2007), bir in P. berghei (Pasini et al. 2013), and cir in P. chabaudi (Lawton et al. 2012); these lead to the major gene families in Plasmodium species (Janssen et al. 2004).

According to the $\mathrm{H}$ strain, $\mathrm{Pk} 1$ (A1) clone nuclear genome sequence, there are $68 \mathrm{kir}$ genes, which give rise to $36-97 \mathrm{kDa}$ proteins. Depending on whether the gene has 2, 3, 4 or 5 exons, the kir genes are classified into types I, II, III and IV, respectively; most of which (90\%) belong to types I and II. The encoded proteins contain 1-3 HMM (Hidden Markov model) domains followed by a transmembrane domain referred to as KIR TM. Collectively, the KIR proteins contain sequences in the extracellular domain with an almost $100 \%$ identity to certain CD99 regions in the host; these represent an example of molecular mimicry - this may play a fundamental role in processes related to immunological resistance given that CD99 is critical to T cell functioning.
The SICAvar gene family (similar to var in P. falciparum)

SICAvar is the largest gene family in P. knowlesi, and is related to immune evasion strategies by variant surface antigenic (VSA) (Al-Khedery et al. 1999). The gene family has 136 genes categorized as type I (with 5-16 exons) or II (with 34 exons) (LAPP et al. 2017). They are dispersed uniformly in the parasite's 14 nuclear chromosomes and encode for a group of SICA proteins, similar to the highly polymorphic protein PfEMP1 of Plasmodium falciparum (GALINSKI et al. 2017).

SICAvar genes were initially reported with a structure of 10 exons encoding for a 205-KDa SICA protein. Subsequently, they were redefined with 12 exons (Lapp et al. 2009). The protein structure to which they give rise, which has a variable number of cysteine-rich domains (CRD), is very similar to that of PfEMP1, although the structure of the genes is very different in both cases, as there are only two exons in P. falciparum; to be precise, the introns begin at the start of the CRD domains. Regardless of whether the genes encoding for the protein are type I or II, the first two exons contain a PEXEL motive and the two final exons encode for a transmembrane domain and a conserved cytoplasmic domain.

\section{Plasmodium malariae}

Historically, Plasmodium malariae and P. ovale infections have not received much attention. This was due, in part, to their low prevalence and the low parasite density caused by either species in humans. Nevertheless, with the greater sensitivity of current molecular techniques, especially whole and deep-genome sequencing, a large number of mixed infections have been examined that contain P. malariae and/or P. ovale together with other Plasmodium spp., thus grabbing the attention of the international scientific community.

Malaria caused by $P$. malariae is characterized by a $72-\mathrm{h}$ fever period, significantly higher than for the rest of the human malaria parasites $(48 \mathrm{~h})$, and it is a chronic yet mild disease. The first draft of the P. malariae nuclear genome was sequenced by Ansari et al. in 2016 from the CDC Uganda I strain (Ansari et al. 2016). Subsequently, a more in-depth analysis was carried out by Rutledge et al. in 2017 (Rutledge et al. 2017). The most reliable data show that the P. malariae nuclear genome is $33.6 \mathrm{Mb}$ in size, having a GC content of approximately $24 \%$ and 6540 genes. The first thing that draws one's attention to this nuclear genome is the presence of two large gene families of highly expanded genes in the subtelomeric region, called fam-m and fam-l. These were initially considered as a single gene family called Pm-fam-a. The curious thing was that they had not been described in any other Plasmodium sp.; in P. malariae, there are almost 700 members. The next gene family found in the nuclear genome was the mir gene family, similar to the pir gene family in $P$. falciparum, with 250 members. There are a similar number 
found in P. falciparum, though there are less than those found in P. vivax (1212). A differential feature is that in P. malariae, almost half of the pir genes are, in fact, pseudogenes. Finally, a third striking finding in the P. malariae genome was a 14-fold copy of a gene encoding for the sexual-stage cytoplasmic protein P27/25. This gene is also found in the P. falciparum genome (only a single copy), and the protein it produces appears at the beginning of gametogenesis (Carter et al. 1989), playing an important role in gametocyte membrane integrity (Olivieri et al. 2009).

\section{The fam- $m$ and fam-I gene families}

Initially, more than 550 genes were grouped into a single highly expanded gene family, Pm-fam-a, encoding for certain proteins that together were related to the 2TM superfamily. In P. malariae, they can have 1-6 predicted TM domains, the majority being proteins in $2 \mathrm{TM}$. Subsequently, further similar genes were identified; these were subdivided into two families, fam- $m$ and fam-l, with 283 and 396 members, respectively. According to the predictions made by Rutledge et al., the proteins encoded by these genes would present as heterodimers, thanks to the joint expression of the fam- $m$ and fam- $l$ doublets on chromosome 5 of $P$. malariae. In most cases, the proteins have a PEXEL export signal peptide that will probably cause them to be exported to the surface of the infected red blood cells. Another interesting fact is that the threedimensional structure of the proteins in these families overlaps perfectly with that of the RH5 protein in P. falciparum (a fundamental protein in erythrocyte invasion), despite the genes encoding for this only having a $10 \%$ sequence similarity. These data point to the important role that the fam-l and fam- $m$ genes play in cell adhesion. On the other hand, approximately half of the members of these families comprise a domain of unknown function, which is also present in $33 P$. vivax and 4 P. knowlesi proteins (Ansari et al. 2016).

\section{Plasmodium ovale}

This parasite was first described in 1922 (Stephens 1922). Two morphologically indistinguishable yet genetically distinct forms were named in 2010: P. ovale curtisi and P. ovale wallikeri (Sutherland et al. 2010). Nonetheless, as with the malaria caused by $P$. malarie, it has received little interest from the international scientific community and from malaria control programs. Nowadays, considering $P$. ovale wallikeri and $P$. ovale curtisi to be distinct species is beyond doubt, not only because of their genetic differences but also because of the diversity observed in their surface antigens. The genome of these two species was analyzed for the first time by Ansari et al. (Ansari et al. 2016) from four genomes (two of each). The two P. ovale wallikeri isolates were obtained from two Chinese workers returning from West Africa. Similarly, a third
Chinese worker provided one of the $P$. ovale curtisi isolates while the other came from the CDC/Nigeria I strain. These genomes have a total length of $33.5 \mathrm{Mb}$, and a GC content of $29 \%$. The $P$. ovale species has a greater number of genes than the other human malaria parasites, with 7132 for $P$. ovale curtisi, and 7052 for P. ovale wallikeri.

The two most important gene families found in the genomes of both species are the Plasmodium interspersed repeats (pir) multi-gene family, which in this case is called oir, and the surfin gene family, which encode for the Surfin protein. For the oir genes, the number of these present in the genome of both $P$. ovale wallikeri and $P$. ovale curtisi is so great (1500-2000), that this fact alone means their genomes are considerably larger than those of other parasites responsible for human malaria, such as P. falciparum $(33.5 \mathrm{Mb}$ vs $23.3 \mathrm{Mb}$ ). This large number of oir genes is common to both $P$. ovale species, indicating that the expansion must have occurred in the proto-ovale ancestral lineage, before speciation occurred (Sutherland and Polley 2011).

Other genes of interest present in the ovale parasite genomes are those that encode for the reticulocytebinding proteins (13-14 genes) and the genes with tryptophan-rich domains (40 genes); these have been proposed as potential candidate antigens for future vaccines; they are also present in other Plasmodium spp. such as P. vivax (Wang et al. 2015).

\section{The surfin gene family}

Surfin (surface-associated interspersed) genes are present in all human malaria parasites but to a much greater degree in the $P$. ovale variants, with 125 genes in $P$. ovale wallikeri and 50 genes in $P$. ovale curtisi. They mostly have a subtelomeric location and usually appear within or adjacent to pir/oir genes. The polymorphic proteins encoded by these genes are transmembrane proteins that are exposed on the surface of both the infected erythrocyte and the merozoite (Winter et al. 2005). As with SICAvar proteins in $P$. knowlesi and PfEMP1 proteins in P. falciparum, SURFIN proteins contain several copies of a tryptophan-rich domain in the cytoplasmic region, known as WRD, the function of which is unknown. In SURFIN proteins, the WRD consists of three blocks: a WRD-A block of 40-60 aa, and two WRD-b blocks of 40-50 aa. The comparative analysis of the conserved sequences in the WRD domain allows us to conclude that SURFIN proteins have an evolutionary origin common to the PfEMP1 and SICAvar proteins (Frech and Chen 2013). On the other hand, an analysis of the modification in the WRD domain expression of these proteins reveals the fundamental role they play in transport from the parasite-derived membranous structures established in the infected red blood cell cytoplasm (called Maurer's clefts) to the membranes (Kagaya et al. 2015). 


\section{Conclusion}

Eradicating malaria has become one of the key challenges facing the World Health Organization. In recent years, enough information has been accumulated on the disease, the parasite and the mosquito vectors to understand that only a global approach can put an end to malaria. The programs used so far have made it possible to control the disease in Europe and North America, with a residual number of cases in both regions. But the problem is in those countries where malaria is a real public health problem. This is the case, for example, in the countries of sub-Saharan Africa. In these, it will be necessary to combine all the tools available to science. One of the tools that more knowledge has generated in recent years are the genomics. Knowing and understanding the information derived from genomic analyses of the parasites causing human malaria should make it possible to approach the eradication of the disease from different fronts. The molecular tools used in recent years, such as next-generation sequencing (NGS), make it possible to attack the disease and act at an epidemiological, treatment or diagnostic level. The great depth obtained with the new bioinformatics approaches, which save a great deal of time and facilitate decision-making, must be added. The development of vaccines, the detection of genes associated with drug resistance, or the knowledge of molecular hot spots in the life cycle of the parasite, have to be addressed in the future in a global manner and taking into account the conscientious analysis of the genomics of Plasmodium. Of course, we cannot ensure that control of all aspects of genomics will lead to end malaria transmission. We are not in a position to know whether that knowledge will be sufficient. But we know that it will be necessary in the development of tools that enable rapid and reliable diagnosis, and that allow us to control adaptive parasite processes. Similarly, molecular tools and genomic knowledge of the parasite must become the cornerstone on which to base the development of one or more effective malaria vaccines. The great genetic variability of the parasite, its complex life cycle and the lack of knowledge about the immune response it triggers are the main stumbling blocks for the development of an effective vaccine. But there is no doubt that the difficulties will be minor relying on genomic knowledge of the disease.

\section{Compliance with ethical standards}

Conflict of interest On behalf of all authors, the corresponding author states that there is no conflict of interest.

\section{References}

Abba K, Kirkham AJ, Olliaro PL, Deeks JJ, Donegan S, Garner P et al (2014) Rapid diagnostic tests for diagnosing uncomplicated nonfalciparum or Plasmodium vivax malaria in endemic countries. Cochrane Database Syst Rev 12
Acharya P, Garg M, Kumar P, Munjal A, Raja KD (2017) Host-parasite interactions in human malaria: clinical implications of basic research. Front Microbiol 8:889

Aguiar JC, Bolton J, Wanga J, Sacci JB, Iriko H, Mazeika JK et al (2015) Discovery of novel Plasmodium falciparum pre-erythrocytic antigens for vaccine development. Silvie O, editor. PLoS One 10(8): e 0136109

Akinosoglou KA, Bushell ESC, Ukegbu CV, Schlegelmilch T, Cho JS, Redmond S et al (2015) Characterization of Plasmodium developmental transcriptomes in Anopheles gambiae midgut reveals novel regulators of malaria transmission. Cell Microbiol 17(2):254-268

Al-Khedery B, Barnwell JW, Galinski MR (1999) Antigenic variation in malaria: a 3 ' genomic alteration associated with the expression of a P. knowlesi variant antigen. Mol Cell 3(2):131-141

Alonso PL, Brown G, Arevalo-Herrera M, Binka F, Chitnis C, Collins F, et al. (2011) A research agenda to underpin malaria eradication. PLoS Medicine. 8,

Alterio V, Di Fiore A, D’Ambrosio K, Supuran CT, De Simone G (2012) Multiple binding modes of inhibitors to carbonic anhydrases: how to design specific drugs targeting 15 different isoforms? Chem Rev 112:4421-4468

de Alvarenga D, de Alvarenga DAM, de Pina-Costa A, de Sousa TN, Pissinatti A, Zalis MG et al (2015) Simian malaria in the Brazilian Atlantic forest: first description of natural infection of capuchin monkeys (Cebinae subfamily) by Plasmodium simium. Malar J 14(1):81

de Alvarenga DAM, Culleton R, de Pina-Costa A, Rodrigues DF, Bianco C, Silva S et al (2018) An assay for the identification of Plasmodium simium infection for diagnosis of zoonotic malaria in the Brazilian Atlantic Forest. Sci Rep [Internet] 8(1):86 Available from: http:// www.nature.com/articles/s41598-017-18216-x

Amambua-Ngwa A, Tetteh KKA, Manske M, Gomez-Escobar N, Stewart LB, Deerhake ME, et al. (2012) Population genomic scan for candidate signatures of balancing selection to guide antigen characterization in malaria parasites. PLoS Genet 8(11)

Amoah LE, Nuvor SV, Obboh EK, Acquah FK, Asare K, Singh SK et al (2017) Natural antibody responses to Plasmodium falciparum MSP3 and GLURP(R0) antigens are associated with low parasite densities in malaria patients living in the central region of Ghana. Parasites Vectors 10(1):1-9

Ansari HR, Templeton TJ, Subudhi AK, Ramaprasad A, Tang J, Lu F et al (2016) Genome-scale comparison of expanded gene families in Plasmodium ovale wallikeri and Plasmodium ovale curtisi with Plasmodium malariae and with other Plasmodium species. Int $\mathrm{J}$ Parasitol 46(11):685-696

Araújo MS, Messias MR, Figueiró MR, Gil LHS, Probst CM, Vidal NM et al (2013) Natural Plasmodium infection in monkeys in the state of Rondônia (Brazilian Western Amazon). Malar J 12(1):180

Ariey F, Witkowski B, Amaratunga C, Beghain J, Langlois AC, Khim N et al (2014) A molecular marker of artemisinin-resistant Plasmodium falciparum malaria. Nature 505(7481):50-55

Arnott A, Barry AE, Reeder JC (2012) Understanding the population genetics of Plasmodium vivax is essential for malaria control and elimination. Malar J 11(1):14

Arredondo SA, Cai M, Takayama Y, MacDonald NJ, Anderson DE, Aravind L et al (2012) Structure of the Plasmodium 6-cysteine s48/45 domain. Proc Natl Acad Sci [Internet] 109(17):6692-6697. Available from: http://www.pnas.org/content/109/17/6692.full. Accessed 14 Apr 2015

Ashley EA, Dhorda M, Fairhurst RM, Amaratunga C, Lim P, Suon S et al (2014) Spread of artemisinin resistance in Plasmodium falciparum malaria. N Engl J Med [Internet] 371(5):411-423. https://doi.org/10. 1056/NEJMoa1314981

Asih PBS, Marantina SS, Nababan R, Lobo NF, Rozi IE, Sumarto W, et al. (2015) Distribution of Plasmodium vivax pvdhfr and pvdhps 
alleles and their association with sulfadoxine-pyrimethamine treatment outcomes in Indonesia. Malar J 14(1)

Assefa S, Lim C, Preston MD, Duffy CW, Nair MB, Adroub SA et al (2015) Population genomic structure and adaptation in the zoonotic malaria parasite Plasmodium knowlesi. Proc Natl Acad Sci [Internet] 112(42):13027-13032 Available from: http://www.pnas.org/ lookup/doi/10.1073/pnas.1509534112

Auburn S, Böhme U, Steinbiss S, Trimarsanto H, Hostetler J, Sanders M et al (2016) A new Plasmodium vivax reference sequence with improved assembly of the subtelomeres reveals an abundance of pir genes. Wellcome Open Res [Internet] 1:4 Available from: https:// wellcomeopenresearch.org/articles/1-4/v1

Baird K (2015) Origins and implications of neglect of G6PD deficiency and primaquine toxicity in Plasmodium vivax malaria. Pathog Glob Health 109(3):93-106

Bansal A, Molina-Cruz A, Brzostowski J, Mu J, Miller LH. Plasmodium falciparum calcium-dependent protein kinase 2 is critical for male gametocyte exflagellation but not essential for asexual proliferation. Sibley LD, editor. MBio 2017 Nov;8(5):e01656-e01617

Barber BE, Rajahram GS, Grigg MJ, William T, Anstey NM (2017) World malaria report: time to acknowledge Plasmodium knowlesi malaria. Malar J 16(1):135

Barillas-Mury C, Kumar S (2005) Plasmodium-mosquito interactions: a tale of dangerous liaisons. Cell Microbiol 7:1539-1545

Barnadas C, Ratsimbasoa A, Tichit M, Bouchier C, Jahevitra M, Picot S et al (2008) Plasmodium vivax resistance to chloroquine in Madagascar: clinical efficacy and polymorphisms in pvmdr1 and pvcrt-o genes. Antimicrob Agents Chemother 52(12):4233-4240

Bartoloni A, Zammarchi L (2012) Clinical aspects of uncomplicated and severe malaria. Mediterr J Hematol Infect Dis 4(1):e2012026

Baton LA, Ranford-Cartwright LC (2005) Do malaria ookinete surface proteins P25 and P28 mediate parasite entry into mosquito midgut epithelial cells? Malaria Journal Vol. 4,

Benavente ED, de Sessions PF, Moon RW, Grainger M, Holder AA, Blackman MJ, et al. (2017a) A reference genome and methylome for the Plasmodium knowlesi A1-H.1 line. International Journal for Parasitology.

Benavente ED, Ward Z, Chan W, Mohareb FR, Sutherland CJ, Roper C, et al. (2017b) Genomic variation in Plasmodium vivax malaria reveals regions under selective pressure. PLoS One 12(5)

Bennink S, Kiesow MJ, Pradel G (2016) The development of malaria parasites in the mosquito midgut. Cell Microbiol 18:905-918

Bergmann-Leitner ES, Li Q, Caridha D, O'Neil MT, Ockenhouse CF, Hickman $M$ et al (2014) Protective immune mechanisms against pre-erythrocytic forms of Plasmodium berghei depend on the target antigen. Trials Vaccinol 3(1):6-10

Bernabeu M, Lopez FJ, Ferrer M, Martin-Jaular L, Razaname A, Corradin G et al (2012) Functional analysis of Plasmodium vivax VIR proteins reveals different subcellular localizations and cytoadherence to the ICAM-1 endothelial receptor. Cell Microbiol 14(3):386-400

Bousema T, Okell L, Felger I, Drakeley C (2014) Asymptomatic malaria infections: detectability, transmissibility and public health relevance. Nat Rev Microbiol 12(12):833-840

Brasil P, Zalis MG, de Pina-Costa A, Siqueira AM, Júnior CB, Silva S, et al. ( 2017) Outbreak of human malaria caused by Plasmodium simium in the Atlantic Forest in Rio de Janeiro: a molecular epidemiological investigation. Lancet Glob Health

Britton S, Cheng Q, McCarthy JS (2016) Novel molecular diagnostic tools for malaria elimination: a review of options from the point of view of high-throughput and applicability in resource limited settings. Malaria Journal Vol. 15

Brugat T, Reid AJ, Lin J, Cunningham D, Tumwine I, Kushinga G et al (2017) Antibody-independent mechanisms regulate the establishment of chronic Plasmodium infection. Nat Microbiol [Internet] 2:
16276 Available from: http://www.nature.com/articles/ nmicrobiol2016276

de Bruin D, Lanzer M, Ravetch J V. The polymorphic subtelomeric regions of Plasmodium falciparum chromosomes contain arrays of repetitive sequence elements. Proc Natl Acad Sci U S A 1994;91(January):619-623

Buery JC, Rodrigues PT, Natal L, Salla LC, Loss AC, Vicente CR et al (2017) Mitochondrial genome of Plasmodium vivax/simium detected in an endemic region for malaria in the Atlantic Forest of Espírito Santo state, Brazil: do mosquitoes, simians and humans harbour the same parasite? Malar J 16(1):437

Burrows J (2015) Microbiology: malaria runs rings round artemisinin. Nature [Internet] 520(7549):628-630 Available from: http://www. nature.com/doifinder/10.1038/nature14387

Buscaglia CA, Coppens I, Hol WGJ, NUssenzweig V (2004) Sites of interaction between aldolase and thrombospondin-related anonymous protein in Plasmodium. Mol Biol Cell 15(April):3751-3737

Bzik DJ, Li WB, Horii T, Inselburg J (1987) Molecular cloning and sequence analysis of the Plasmodium falciparum dihydrofolate reductase-thymidylate synthase gene. Proc Natl Acad Sci U S A [Internet] 84(23):8360-8364 Available from: http://www. pubmedcentral.nih.gov/articlerender.fcgi?artid=299542\&tool= pmcentrez\&rendertype $=$ abstract

Calvo N, Morera J, Dolz G, et al (2015) Re-emergence of Plasmodium malariae in Costa Rica. Sci Postprint. https://doi.org/10.14340/spp. 2015.04A0004

de Camargo TM, de Freitas EO, Gimenez AM, Lima LC, de Almeida CK, Françoso KS et al (2018) Prime-boost vaccination with recombinant protein and adenovirus-vector expressing Plasmodium vivax circumsporozoite protein (CSP) partially protects mice against $\mathrm{Pb}$ / Pv sporozoite challenge. Sci Rep [Internet] 8(1):1118 Available from: http://www.nature.com/articles/s41598-017-19063-6

Carlton J (2003) The Plasmodium vivax genome sequencing project. Trends in Parasitology 19:227-231

Carlton JM, Adams JH, Silva JC, Bidwell SL, Lorenzi H, Caler E et al (2008) Comparative genomics of the neglected human malaria parasite Plasmodium vivax. Nature 455(7214):757-763

Carter R, Coulson A, Bhatti S, Taylor BJ, Elliott JF (1995) Predicted disulphide-bonded structures for three uniquely related proteins of Plasmodium falciparum, Pfs230, Pfs48/45 and pf12. Mol Biochem Parasitol 71(2):203-210

Carter R, Graves PM, Creasey A, Byrne K, Read D, Alano P et al (1989) Plasmodium falciparum: an abundant stage-specific protein expressed during early gametocyte development. Exp Parasitol 69(1):140-149

Carter R, Mendis KN (2002) Evolutionary and historical aspects of the burden of malaria evolutionary and historical aspects of the burden of malaria. Clin Microbiol Rev 15(4):564-594

Ceesay SJ, Casals-Pascual C, Erskine J, Anya SE, Duah NO, Fulford AJ et al (2008) Changes in malaria indices between 1999 and 2007 in the Gambia: a retrospective analysis. Lancet 372(9649):1545-1554

Chang H-H, Moss EL, Park DJ, Ndiaye D, Mboup S, Volkman SK et al (2013) Malaria life cycle intensifies both natural selection and random genetic drift. Proc Natl Acad Sci [Internet] 110(50):2012920134 Available from: http://www.pnas.org/cgi/doi/10.1073/pnas. 1319857110

Chaurio RA, Pacheco MA, Cornejo OE, Durrego E, Stanley CE, Castillo AI, et al. (2016) Evolution of the transmission-blocking vaccine candidates Pvs28 and Pvs25 in Plasmodium vivax: geographic differentiation and evidence of positive selection. PLoS Negl Trop Dis 10(6)

Cheeseman IH, Miller BA, Nair S, Nkhoma S, Tan A, Tan JC, et al. (2012) A major genome region underlying artemisinin resistance in malaria. Science (80-). 335(6077):79-82 
Chen I, Clarke SE, Gosling R, Hamainza B, Killeen G, Magill A et al (2016) "Asymptomatic" malaria: a chronic and debilitating infection that should be treated. PLoS Med 13(1):1-11

Chen Q, Fernandez V, Sundström A, Schlichtherle M, Datta S, Hagblom $P$ et al (1998) Developmental selection of var gene expression in Plasmodium falciparum. Nature [Internet] 394(6691):392-395 Available from: http://www.nature.com/doifinder/10.1038/28660

Chen SB, Wang Y, Kassegne K, Xu B, Shen HM, Chen JH (2017) Whole-genome sequencing of a Plasmodium vivax clinical isolate exhibits geographical characteristics and high genetic variation in China-Myanmar border area. BMC Genomics 18(1)

Cheng Q, Gatton ML, Barnwell J, Chiodini P, McCarthy J, Bell D, et al. (2014) Plasmodium falciparum parasites lacking histidine-rich protein 2 and 3: a review and recommendations for accurate reporting. Malar J 13(1)

Chinchilla M, Guerrero OM, Gutiérrez G, Sánchez R (2006) Presencia de Plasmodium brasilianum (Apicomplexa, Plasmodidae) en el mono congo (Alouatta palliata, Primates: Cebidae) de Costa Rica: Importancia epidemiológica en relación con el ser humano. Parasitol Latinoam 61(3-4):192-196

Cholera R, Brittain NJ, Gillrie MR, Lopera-Mesa TM, Diakité SAS, Arie $\mathrm{T}$ et al (2008) Impaired cytoadherence of Plasmodium falciparuminfected erythrocytes containing sickle hemoglobin. Proc Natl Acad Sci U S A 105(3):991-996

Claessens A, Hamilton WL, Kekre M, Otto TD, Faizullabhoy A, Rayner JC, et al. (2014) Generation of antigenic diversity in Plasmodium falciparum by structured rearrangement of var genes during mitosis. PLoS Genet 10(12)

Clyde DF, Most H, McCarthy VC, Vanderberg JP, Al E (1973) Immunization of man against sporozite-induced falciparum malaria. Am J Med Sci 266(3):169-177

Cohen S, McGregor IA, Carrington S (1961) Gamma-globulin and acquired immunity to human malaria. Nature 192(4804):733-737

Collins WE (2002) Nonhuman primate models. In: Malaria Methods and Protocols [Internet]. p. 77-84. Available from: https://doi.org/10. 1385/1-59259-271-6:77

Collins WE, Jeffery GM (2007) Plasmodium malariae: parasite and disease. Clin Microbiol Rev 20:579-592

Conway DJ (2015) Paths to a malaria vaccine illuminated by parasite genomics. Trends in Genetics 31:97-107

Coppi A, Natarajan R, Pradel G, Bennett BL, James ER, Roggero MA et al (2011) The malaria circumsporozoite protein has two functional domains, each with distinct roles as sporozoites journey from mosquito to mammalian host. J Exp Med [Internet] 208(2):341-356 Available from: http://www.jem.org/lookup/doi/10.1084/jem. 20101488

Costa DC, da Cunha VP, de Assis GMP, de Souza Junior JC, Hirano ZMB, de Arruda ME et al (2014) Plasmodium simium/ Plasmodium vivax infections in southern brown howler monkeys from the Atlantic Forest. Mem Inst Oswaldo Cruz 109(5):641-653

Cowell AN, Istvan ES, Lukens AK, Gomez-Lorenzo MG, Vanaerschot M, Sakata-Kato T, et al. (2018) Mapping the malaria parasite druggable genome by using in vitro evolution and chemogenomics. Science (80-). 359(6372):191-9

Cowman AF, Karcz S, Galatis D, Culvenor JG (1991) A P-glycoprotein homologue of Plasmodium falciparum is localized on the digestive vacuole. J Cell Biol 113(5):1033-1042

Cowman AF, Tonkin CJ, Tham W-H, Duraisingh MT (2017) The molecular basis of erythrocyte invasion by malaria parasites. Cell Host Microbe [Internet] 22(2):232-245 Available from: http:// linkinghub.elsevier.com/retrieve/pii/S193131281730286X

Cubi R, Vembar SS, Biton A, Franetich JF, Bordessoulles M, Sossau D, et al. (2017) Laser capture microdissection enables transcriptomic analysis of dividing and quiescent liver stages of Plasmodium relapsing species. Cell Microbiol 19(8)
D'Alessandro HTU, Sorgho H, Valea I (2015) Efficacy and safety of RTS,S/AS01 malaria vaccine with or without a booster dose in infants and children in Africa: final results of a phase 3, individually randomised, controlled trial. Lancet 386(9988):31-45

Datta D, Bansal GP, Gerloff DL, Ellefsen B, Hannaman D, Kumar N (2017) Immunogenicity and malaria transmission reducing potency of Pfs $48 / 45$ and Pfs 25 encoded by DNA vaccines administered by intramuscular electroporation. Vaccine 35(2):264-272

Deane LM, Deane LM (1992) Simian malaria in Brazil. Mem Inst Oswaldo Cruz 87(suppl 3):1-20

Van Dijk MR, Janse CJ, Thompson J, Waters AP, Braks JAM, Dodemont $\mathrm{HJ}$ et al (2001) A central role for P48/45 in malaria parasite male gamete fertility. Cell 104(1):153-164

Dinko B, Oguike MC, Larbi JA, Bousema T, Sutherland CJ (2013) Persistent detection of Plasmodium falciparum, P. malariae, P. ovale curtisi and P. ovale wallikeri after ACT treatment of asymptomatic Ghanaian school-children. Int J Parasitol Drugs Drug Resist 3:4550

Doolan DL, Apte SH, Proietti C (2014) Genome-based vaccine design: the promise for malaria and other infectious diseases. Int J Parasitol 44:901-913

Draper SJ, Angov E, Horii T, Miller LH, Srinivasan P, Theisen M et al (2015) Recent advances in recombinant protein-based malaria vaccines. Vaccine 33(52):7433-7443

Ejigiri I, Sinnis P (2009) Plasmodium sporozoite-host interactions from the dermis to the hepatocyte. Curr Opin Microbiol 12:401-407

Eldering M, Bompard A, Miura K, Stone W, Morlais I, Cohuet A, et al. (2017) Comparative assessment of An. gambiae and An. stephensi mosquitoes to determine transmission-reducing activity of antibodies against $\mathrm{P}$. falciparum sexual stage antigens. Parasites Vectors $10(1)$

Espinosa DA, Vega-Rodriguez J, Flores-Garcia Y, Noe AR, Muñoz C, Coleman R et al (2017) The Plasmodium falciparum cell-traversal protein for ookinetes and sporozoites as a candidate for preerythrocytic and transmission-blocking vaccines. Infect Immun [Internet] 85(2):1-10 Available from: https://www.ncbi.nlm.nih. gov/pmc/articles/PMC5278177/pdf/e00498-16.pdf

Fançony C, Gamboa D, Sebastião Y, Hallett R, Sutherland C, SousaFigueiredo JC et al (2012) Various pfcrt and pfmdr1 genotypes of Plasmodium falciparum cocirculate with P. malariae, P. ovale spp., and P. vivax in northern Angola. Antimicrob Agents Chemother 56(10):5271-5277

Fernández-Becerra C, Pinazo M, González A, Alonso PL, del Portillo HA, Gascón J (2009) Increased expression levels of the pvcrt-o and pvmdr1 genes in a patient with severe Plasmodium vivax malaria. Malar J 8(1):55

Fernandez-Becerra C, Yamamoto MM, Vêncio RZN, Lacerda M, Rosanas-Urgell A, del Portillo HA (2009) Plasmodium vivax and the importance of the subtelomeric multigene vir superfamily. Trends in Parasitology 25:44-51

Figueiredo MAP, Di Santi SM, Manrique WG, André MR, Machado RZ (2017) Identification of Plasmodium spp. in Neotropical primates of Maranhense Amazon in Northeast Brazil. PLoS One 12(8):1-14

Filipe JAN, Riley EM, Drakeley CJ, Sutherland CJ, Ghani AC (2007) Determination of the processes driving the acquisition of immunity to malaria using a mathematical transmission model. PLoS Comput Biol 3(12):e255

Flick K, var genes Chen Q (2004) PfEMP1 and the human host. Mol Biochem Parasitol 134:3-9

Fonager J, Cunningham D, Jarra W, Koernig S, Henneman AA, Langhorne $J$ et al (2007) Transcription and alternative splicing in the yir multigene family of the malaria parasite Plasmodium y. yoelii: identification of motifs suggesting epigenetic and posttranscriptional control of RNA expression. Mol Biochem Parasitol 156(1):1-11

Formaglio P, Amino R (2015 Oct) Looking for blood. elife 4 
Foth BJ, McFadden GI (2003) The apicoplast: a plastid in plasmodium falciparum and other apicomplexan parasites. Int Rev Cytol 224:57110

Frech C, Chen N (2013) Variant surface antigens of malaria parasites: functional and evolutionary insights from comparative gene family classification and analysis. BMC Genomics 14(1)

Fuentes-Ramírez A, Jiménez-Soto M, Castro R, Romero-Zuñiga JJ, Dolz G (2017) Molecular detection of Plasmodium malariae/Plasmodium brasilianum in non-human primates in captivity in Costa Rica. PLoS One 12(1):1-12

Galinski MR, Lapp SA, Peterson MS, Ay F, Joyner CJ, Roch KG LE et al (2017) Plasmodium knowlesi: a superb in vivo nonhuman primate model of antigenic variation in malaria. Parasitology:1-16

Garcia JE, Puentes A, Patarroyo ME (2006) Developmental biology of sporozoite-host interactions in Plasmodium falciparum malaria: implications for vaccine design. Clin Microbiol Rev 19:686-707

Gardner MJ, Hall N, Fung E, White O, Berriman M, Hyman RW et al (2002) Genome sequence of the human malaria parasite Plasmodium falciparum. Nature [Internet] 419(6906):498-511 Available from: http://www.nature.com/doifinder/10.1038/ nature 01097

Garrido-Cardenas JA, Garcia-Maroto F, Alvarez-Bermejo JA, ManzanoAgugliaro F (2017) DNA sequencing sensors : an overview. Sensors (Basel) 17 (3)(588):1-15

Gerloff DL, Creasey A, Maslau S, Carter R (2005) Structural models for the protein family characterized by gamete surface protein Pfs 230 of Plasmodium falciparum. Proc Natl Acad Sci U S A [Internet] 102(38):13598-13603 Available from: http://www.ncbi.nlm.nih. gov/entrez/query.fcgi? $\mathrm{cmd}=$ Retrieve $\& \mathrm{db}=\mathrm{PubMed} \& \mathrm{dopt}=$ Citation\&list uids $=16155126$

Ghosh AK, Coppens I, Gardsvoll H, Ploug M, Jacobs-Lorena M (2011) Plasmodium ookinetes coopt mammalian plasminogen to invade the mosquito midgut. Proc Natl Acad Sci [Internet] 108(41):1715317158 Available from: http://www.pnas.org/cgi/doi/10.1073/pnas. 1103657108

Gillrie MR, Renaux B, Russell-Goldman E, Avril M, Brazier AJ, Mihara K et al (2016 Sep) Thrombin cleavage of Plasmodium falciparum erythrocyte membrane protein 1 inhibits cytoadherence. MBio 7(5): e01120-e01116

Gilson PR, Crabb BS (2009) Morphology and kinetics of the three distinct phases of red blood cell invasion by Plasmodium falciparum merozoites. Int J Parasitol 39(1):91-96

Ginouves M, Veron V, Musset L, Legrand E, Stefani A, Prevot G et al (2015) Frequency and distribution of mixed Plasmodium falciparum-vivax infections in French Guiana between 2000 and 2008. Malar J 14(1):446

Golassa L, Baliraine FN, Enweji N, Erko B, Swedberg G, Aseffa A (2015) Microscopic and molecular evidence of the presence of asymptomatic Plasmodium falciparum and Plasmodium vivax infections in an area with low, seasonal and unstable malaria transmission in Ethiopia. BMC Infect Dis 15:310

Gonçalves BP, Drakeley C, Bousema T (2016) Infectivity of microscopic and submicroscopic malaria parasite infections in areas of low malaria endemicity. J Infect Dis 213(9):1516-1517

González-Cerón L, Alvarado-Delgado A, Martínez-Barnetche J, Rodríguez MH, Ovilla-Muñoz M, Pérez F et al (2010) Sequence variation of ookinete surface proteins Pvs25 and Pvs28 of Plasmodium vivax isolates from southern Mexico and their association to local anophelines infectivity. Infect Genet Evol 10(5):645-654

Goodman CD, Siregar JE, Mollard V, Vega-Rodríguez J, Syafruddin D, Matsuoka H, et al. (2016) Parasites resistant to the antimalarial atovaquone fail to transmit by mosquitoes. Science (80-) 352(6283):349-53

Gregson A, Plowe CV (2005) Mechanisms of resistance of malaria parasites to antifolates. Pharmacol Rev 57(1):117-145
Grigg MJ, Snounou G (2017) Plasmodium simium: a Brazilian focus of anthropozoonotic vivax malaria? Lancet Glob Heal 17:961-962

Guimarães LO, Bajay MM, Wunderlich G, Bueno MG, Röhe F, CatãoDias JL et al (2012) The genetic diversity of Plasmodium malariae and Plasmodium brasilianum from human, simian and mosquito hosts in Brazil. Acta Trop 124(1):27-32

Hall N, Karras M, Raine JD, Carlton JM, Kooij TWA, Berriman M, et al. (2005) A comprehensive survey of the Plasmodium life cycle by genomic, transcriptomic, and proteomic analyses. Science (80-) 307(5706):82-6

Hamad AA, El Hassan IM, El Khalifa AA, Ahmed GI, Abdelrahim SA, Theander TG et al (2000) Chronic Plasmodium falciparum infections in an area of low intensity malaria transmission in the Sudan. Parasitology 120(5):447-456

Hastings MD, Maguire JD, Bangs MJ, Zimmerman PA, Reeder JC, Baird JK et al (2005) Novel Plasmodium vivax dhfr alleles from the Indonesian archipelago and Papua New Guinea: association with pyrimethamine resistance determined by a Saccharomyces cerevisiae expression system. Antimicrob Agents Chemother 49:733-740

Hay SI, Guerra CA, Tatem AJ, Noor AM, Snow RW (2004) The global distribution and population at risk of malaria: past, present, and future. Lancet Infect Dis 4(6):327-336

Herdiana H, Cotter C, Coutrier FN, Zarlinda I, Zelman BW, Tirta YK et al (2016) Malaria risk factor assessment using active and passive surveillance data from Aceh Besar, Indonesia, a low endemic, malaria elimination setting with Plasmodium knowlesi, Plasmodium vivax, and Plasmodium falciparum. Malar J 15(1):468

Hermsen CC, Verhage DF, Telgt DSC, Teelen K, Bousema JT, Roestenberg $\mathrm{M}$ et al (2007) Glutamate-rich protein (GLURP) induces antibodies that inhibit in vitro growth of Plasmodium falciparum in a phase 1 malaria vaccine trial. Vaccine 25(15): 2930-2940

Hikosaka K, Watanabe Y i, Kobayashi F, Waki S, Kita K, Tanabe K (2011) Highly conserved gene arrangement of the mitochondrial genomes of 23 Plasmodium species. Parasitol Int 60(2):175-180

Hoffman SL, Goh LML, Luke TC, Schneider I, Le TP, Doolan DL et al (2002) Protection of humans against malaria by immunization with radiation-attenuated Plasmodium falciparum sporozoites. J Infect Dis [Internet] 185(8):1155-1164 Available from: http://www.ncbi. nlm.nih.gov/pubmed/11930326

Hoffman SL, Vekemans J, Richie TL, Duffy PE (2015) The march toward malaria vaccines. Am J Prev Med 49:S319-S333

Horii T, Shirai H, Jie L, Ishii KJ, Palacpac NQ, Tougan T et al (2010) Evidences of protection against blood-stage infection of Plasmodium falciparum by the novel protein vaccine SE36. Parasitol Int 59(3):380-386

Howes RE, Battle KE, Mendis KN, Smith DL, Cibulskis RE, Baird JK et al (2016) Global epidemiology of Plasmodium vivax. Am J Trop Med Hyg [Internet] 95(6 Suppl):15-34 Available from: http://www. pubmedcentral.nih.gov/articlerender.fcgi?artid=5198891\&tool= pmcentrez\&rendertype $=$ abstract

Huang B, Huang S, Su XZ, Tong X, Yan J, Li H et al (2014) Molecular surveillance of pvdhfr, pvdhps, and pvmdr-1 mutations in Plasmodium vivax isolates from Yunnan and Anhui provinces of China. Malar J 13(1):1-10

Hupalo DN, Luo Z, Melnikov A, Sutton PL, Rogov P, Escalante A et al (2016) Population genomics studies identify signatures of global dispersal and drug resistance in Plasmodium vivax. Nat Genet 48(8):953-958

Imwong M, Nakeesathit S, Day NP, White NJ (2011) A review of mixed malaria species infections in anopheline mosquitoes. Malar J 10(1): 253

Janssen CS, Barrett MP, Turner CMR, Phillips RS (2002) A large gene family for putative variant antigens shared by human and rodent malaria parasites. Proc Biol Sci [Internet] 269(1489):431-436 
Available from: http://www.pubmedcentral.nih.gov/articlerender. fcgi?artid=1690903\&tool=pmcentrez\&rendertype $=$ abstract

Janssen CS, Phillips RS, Turner MR, Barret MP (2004) Plasmodium interspersed repeats: the major multigene superfamily of malaria parasites. Nucleic Acids Res 32(19):5712-5720

Kagaya W, Miyazaki S, Yahata K, Ohta N, Kaneko O (2015) The cytoplasmic region of Plasmodium falciparum SURFIN4.2 is required for transport from Maurer's clefts to the red blood cell surface. Trop Med Health [Internet] 43(4):265-272 Available from: http://www. ncbi.nlm.nih.gov/pubmed/26865830\%5Cn, http://www. pubmedcentral.nih.gov/articlerender.fcgi?artid=PMC4689606

Kantele A, Jokiranta TS (2011) Review of cases with the emerging fifth human malaria parasite, Plasmodium knowlesi. Clin Infect Dis [Internet] 52(11):1356-1362 Available from: http://www.ncbi.nlm. nih.gov/pubmed/21596677

Kariu T, Ishino T, Yano K, Chinzei Y, Yuda M (2006) CelTOS, a novel malarial protein that mediates transmission to mosquito and vertebrate hosts. Mol Microbiol 59(5):1369-1379

de Koning-Ward TF, Gilson PR, Boddey JA, Rug M, Smith BJ, Papenfuss AT et al (2009) A newly discovered protein export machine in malaria parasites. Nature [Internet] 459(7249):945-949 Available from: http://www.nature.com/doifinder/10.1038/ nature 08104

Krungkrai J, Krungkrai SR, Supuran CT (2008) Carbonic anhydrase inhibitors: inhibition of Plasmodium falciparum carbonic anhydrase with aromatic/heterocyclic sulfonamides-in vitro and in vivo studies. Bioorganic Med Chem Lett 18(20):5466-5471

Krungkrai SR, Krungkrai J (2011) Malaria parasite carbonic anhydrase: inhibition of aromatic/heterocyclic sulfonamides and its therapeutic potential. Asian Pac J Trop Biomed 1(3):233-242

Kulangara C, Luedin S, Dietz O, Rusch S, Frank G, Mueller D, et al. (2012) Cell biological characterization of the malaria vaccine candidate trophozoite exported protein 1. PLoS One 7(10)

Lal K, Prieto JH, Bromley E, Sanderson SJ, Yates JR, Wastling JM et al (2009) Characterisation of Plasmodium invasive organelles; an ookinete microneme proteome. Proteomics 9(5):1142-1151

Lalremruata A, Jeyaraj S, Engleitner T, Joanny F, Lang A, Bélard S, et al. (2017) Species and genotype diversity of Plasmodium in malaria patients from Gabon analysed by next generation sequencing. Malar J 16(1)

Lalremruata A, Magris M, Vivas-Martinez S, Koehler M, Esen M, Kempaiah P et al (2015) Natural infection of Plasmodium brasilianum in humans: man and monkey share quartan malaria parasites in the Venezuelan Amazon. EBioMedicine 2(9):1186-1192

LAPP SA, GERALDO JA, CHIEN JT, AY F, PAKALA SB, BATUGEDARA G, et al. (2017) PacBio assembly of a Plasmodium knowlesi genome sequence with $\mathrm{Hi}-\mathrm{C}$ correction and manual annotation of the SICAvar gene family. Parasitology:1-14

Lapp SA, Korir CC, Galinski MR (2009) Redefining the expressed prototype SICAvar gene involved in plasmodium knowlesi antigenic variation. Malar J 8(1)

Lasonder E, Rijpma SR, Van Schaijk BCL, Hoeijmakers WAM, Kensche PR, Gresnigt MS et al (2016) Integrated transcriptomic and proteomic analyses of $\mathrm{P}$. falciparum gametocytes: molecular insight into sex-specific processes and translational repression. Nucleic Acids Res 44(13):6087-6101

Lavstsen T, Salanti A, Jensen ATR, Arnot DE, Theander TG (2003) Subgrouping of Plasmodium falciparum 3D7 var genes based on sequence analysis of coding and non-coding regions. Malar J [Internet] 2:27. Available from: http://www.pubmedcentral.nih. gov/articlerender.fcgi?artid $=222925 \&$ tool $=$ pmcentrez\&rendertype $=$ abstract

Lawton J, Brugat T, Yan YX, Reid AJ, Böhme U, Otto TD et al (2012) Characterization and gene expression analysis of the cir multi-gene family of Plasmodium chabaudi chabaudi (AS). BMC Genomics [Internet] 13(1):-125 Available from: http://www.pubmedcentral. nih.gov/articlerender.fcgi $?$ artid $=3384456 \&$ tool $=$ pmcentrez\&rendertype $=$ abstract

Lee KS, Divis PCS, Zakaria SK, Matusop A, Julin RA, Conway DJ, et al. (2011) Plasmodium knowlesi: reservoir hosts and tracking the emergence in humans and macaques. PLoS Pathog 7(4)

Lee S, Nguyen MT (2015) Recent advances of vaccine adjuvants for infectious diseases. Immune Netw [Internet] 15(2):51 Available from: https://synapse.koreamed.org/DOIx.php?id=10.4110/in. 2015.15.2.51

Lee SM, Wu CK, Plieskatt JL, Miura K, Hickey JM, King CR (2017) Nterminal Pfs230 domain produced in baculovirus as a biological active transmission-blocking vaccine candidate. Clin Vaccine Immunol 24(10)

Li B, Sun Z, Li X, Li X, Wang H, Chen W et al (2017) Performance of pfHRP2 versus $\mathrm{pLDH}$ antigen rapid diagnostic tests for the detection of Plasmodium falciparum: a systematic review and meta-analysis. Arch Med Sci 13:541-549

Li F, Bounkeua V, Pettersen K, Vinetz JM (2016) Plasmodium falciparum ookinete expression of plasmepsin VII and plasmepsin X. Malar J 15(1)

Li F, Templeton TJ, Popov V, Comer JE, Tsuboi T, Torii M, et al. Plasmodium ookinete-secreted proteins secreted through a common micronemal pathway are targets of blocking malaria transmission. In: Journal of Biological Chemistry. 2004. p. 26635-44

Lin CS, Uboldi AD, Epp C, Bujard H, Tsuboi T, Czabotar PE et al (2016) Multiple plasmodium falciparum merozoite surface protein $1 \mathrm{com}-$ plexes mediate merozoite binding to human erythrocytes. J Biol Chem 291(14):7703-7715

Lin JT, Saunders DL, Meshnick SR (2014 Apr) The role of submicroscopic parasitemia in malaria transmission: what is the evidence? Trends Parasitol 30(4):183-190

Lindblade KA, Steinhardt L, Samuels A, Kachur SP, Slutsker L (2013) The silent threat: asymptomatic parasitemia and malaria transmission. Expert Rev Anti-Infect Ther 11(6):623-639

López C, Saravia C, Gomez A, Hoebeke J, Patarroyo MA (2010) Mechanisms of genetically-based resistance to malaria. Gene 467(1-2):1-12

Lubis IND, Wijaya H, Lubis M, Lubis CP, Divis PCS, Beshir KB et al (2017) Contribution of Plasmodium knowlesi to multispecies human malaria infections in north Sumatera, Indonesia. J Infect Dis 215(7):1148-1155

Maeno Y (2017) Molecular epidemiology of mosquitoes for the transmission of forest malaria in south-central Vietnam. Tropical Med Health Vol. 45

Magesa SM, Mdira KY, Babiker HA, Alifrangis M, Färnert A, Simonsen PE et al (2002 Nov) Diversity of Plasmodium falciparum clones infecting children living in a holoendemic area in north-eastern Tanzania. Acta Trop 84(2):83-92

Maitland K. (2016) Severe malaria in African children - the need for continuing investment. Sev Malar African Child n engl j med 37525

Makhtar Niang, Amy Kristine Bei, Kripa Gopal Madnani, Shaaretha Pelly, Selasi Dankwa, Usheer Kanjee, Karthigayan Gunalan, Anburaj Amaladoss KPY, Ndeye Sakha Bob, Benoit Malleret, , Manoj Duraisingh and PRP. The variant STEVOR protein of Plasmodium falciparum is a red cell binding protein important for merozoite invasion and rosetting. Cell Host Microbe 2014;16(1):81-93

Malmberg M, Ferreira PE, Tarning J, Ursing J, Ngasala B, Björkman A et al (2013) Plasmodium falciparum drug resistance phenotype as assessed by patient antimalarial drug levels and its association with pfmdr1 polymorphisms. J Infect Dis 207(5):842-847

Markus MB (2011) The hypnozoite concept, with particular reference to malaria. Parasitol Res 108:247-252

Martin RE, Marchetti R V., Cowan AI, Howitt SM, Broer S, Kirk K (2009) Chloroquine transport via the malaria parasite's chloroquine resistance transporter. Science (80- ) [Internet] 325(5948):1680-2. Available from: http://www.sciencemag.org/cgi/doi/10.1126/ science. 1175667 
Mbengue A, Bhattacharjee S, Pandharkar T, Liu H, Estiu G, Stahelin RV et al (2015) A molecular mechanism of artemisinin resistance in Plasmodium falciparum malaria. Nature [Internet] 520(7549):683687 Available from: http://www.nature.com/doifinder/10.1038/ nature 14412

McCollum AM, Basco LK, Tahar R, Udhayakumar V, Escalante AA (2008) Hitchhiking and selective sweeps of Plasmodium falciparum sulfadoxine and pyrimethamine resistance alleles in a population from central Africa. Antimicrob Agents Chemother 52(11):40894097

Ménard R, Tavares J, Cockburn I, Markus M, Zavala F, Amino R (2013) Looking under the skin: the first steps in malarial infection and immunity. Nat Rev Microbiol 11(10):701-712

Millar SB, Cox-Singh J (2015) Human infections with Plasmodium knowlesi-zoonotic malaria. Clin Microbiol Infect 21(7):640-648

Mills JP, Diez-Silva M, Quinn DJ, Dao M, Lang MJ, Tan KSW et al (2007) Effect of plasmodial RESA protein on deformability of human red blood cells harboring Plasmodium falciparum. Proc Natl Acad Sci [Internet] 104(22):9213-9217 Available from: http://www. pnas.org/cgi/doi/10.1073/pnas.0703433104

Miotto O, Amato R, Ashley EA, MacInnis B, Almagro-Garcia J, Amaratunga $\mathrm{C}$ et al (2015) Genetic architecture of artemisininresistant Plasmodium falciparum. Nat Genet [Internet] 47(3):226234 Available from: http://www.nature.com/doifinder/10.1038/ng. 3189

Miura K (2016) Progress and prospects for blood-stage malaria vaccines. Expert Rev Vaccines 15:765-781

Mobegi VA, Duffy CW, Amambua-Ngwa A, Loua KM, Laman E, Nwakanma DC et al (2014) Genome-wide analysis of selection on the malaria parasite plasmodium falciparum in West African populations of differing infection endemicity. Mol Biol Evol 31(6):14901499

Modrzynska K, Pfander C, Chappell L, Yu L, Suarez C, Dundas K et al (2017) A knockout screen of ApiAP2 genes reveals networks of interacting transcriptional regulators controlling the Plasmodium life cycle. Cell Host Microbe 21(1):11-22

Mohan, K., Stevenson MM (1998) Acquired immunity to asexual blood stages. . In: Sherman, I.W. (Ed.), Malaria: parasite biology, pathogenesis and protection. ASM press, Washington, D. C

Molina-Cruz A, Canepa GE, Kamath N, Pavlovic NV, Mu J, Ramphul UN et al (2015) Plasmodium evasion of mosquito immunity and global malaria transmission: The lock-and-key theory. Proc Natl Acad Sci [Internet] 112(49):15178-15183 Available from: http:// www.pnas.org/lookup/doi/10.1073/pnas.1520426112

Molina-Cruz A, Garver LS, Alabaster A, Bangiolo L, Haile A, Winikor J, et al. (2013) The human malaria parasite Pfs47 gene mediates evasion of the mosquito immune system. Science (80-) 340(6135):984 7

Moorthy VS, Newman RD, Okwo-Bele J-M (2013) Malaria Vaccine Funders Group. Malaria Vaccine Technology Roadmap [Internet]. Lancet 382:1700-1. Available from: http://www.thelancet.com/ journals/a/article/PIIS0140-6736(13)62238-2/fulltext\%5Cnhttp:// www.ncbi.nlm.nih.gov/pubmed/24239252

Mordmüller B, Surat G, Lagler H, Chakravarty S, Ishizuka AS, Lalremruata A et al (2017) Sterile protection against human malaria by chemoattenuated PfSPZ vaccine. Nature 542(7642):445-449

Moreira CK, Naissant B, Coppi A, Bennett BL, Aime E, Franke-Fayard B, et al. (2016) The plasmodium PHIST and RESA-like protein families of human and rodent malaria parasites. PLoS One 11(3)

Moreira CK, Templeton TJ, Lavazec C, Hayward RE, Hobbs CV, Kroeze $\mathrm{H}$ et al (2008) The Plasmodium TRAP/MIC2 family member, TRAP-like protein (TLP), is involved in tissue traversal by sporozoites. Cell Microbiol 10(7):1505-1516

Moreno M, Marinotti O, Krzywinski J, Tadei WP, James AA, Achee NL, et al. (2010) Complete mtDNA genomes of Anopheles darlingi and an approach to anopheline divergence time. Malar J 9(1)
Mueller I, Galinski MR, Tsuboi T, Arevalo-Herrera M, Collins WE, King CL (2013) Natural acquisition of immunity to Plasmodium vivax. In: Advances in parasitology. p. 77-131

Mueller I, Shakri AR, Chitnis CE (2015) Development of vaccines for Plasmodium vivax malaria. Vaccine 33(52):7489-7495

Mwanza S, Joshi S, Nambozi M, Chileshe J, Malunga P, Kabuya J-BB et al (2016) The return of chloroquine-susceptible Plasmodium falciparum malaria in Zambia. Malar J [Internet] 15(1):584 Available from: http://malariajournal.biomedcentral.com/articles/ 10.1186/s12936-016-1637-3

Naing C, Whittaker MA, Nyunt Wai V, Mak JW (2014) Is Plasmodium vivax malaria a severe malaria?: a systematic review and meta-analysis. PLoS Negl Trop Dis 8(8)

Nyboer B, Heiss K, Mueller A-K, Ingmundson A (2017) The Plasmodium liver-stage parasitophorous vacuole: a front-line of communication between parasite and host. Int J Med Microbiol. (August):0-1

O'Meara WP, Mwangi TW, Williams TN, McKenzie FE, Snow RW, Marsh K (2008) Relationship between exposure, clinical malaria, and age in an area of changing transmission intensity. Am J Trop Med Hyg 79(2):185-191

Ohta T (2000) Evolution of gene families. Gene 259(1-2):45-52

Olivieri A, Camarda G, Bertuccini L, Van De Vegte-Bolmer M, Luty AJF, Sauerwein R et al (2009) The Plasmodium falciparum protein Pfg27 is dispensable for gametocyte and gamete production, but contributes to cell integrity during gametocytogenesis. Mol Microbiol 73(2):180-193

Olszewski KL, Morrisey JM, Wilinski D, Burns JM, Vaidya AB, Rabinowitz JD et al (2009) Host-parasite interactions revealed by Plasmodium falciparum metabolomics. Cell Host Microbe 5(2): 191-199

Ouédraogo AL, Bousema T, Schneider P, de Vlas SJ, Ilboudo-Sanogo E, Cuzin-Ouattara N, et al. (2009) Substantial contribution of submicroscopical Plasmodium falciparum gametocyte carriage to the infectious reservoir in an area of seasonal transmission. Diemert DJ, editor. PLoS One. 4(12):e8410

Pacheco MA, Matta NE, Valkiūnas G, Parker PG, Mello B, Stanley CE, et al. (2017) Mode and rate of evolution of haemosporidian mitochondrial genomes: timing the radiation of avian parasites. Mol Biol Evol [Internet]. Available from: http://academic.oup.com/mbe/ advance-article/doi/10.1093/molbev/msx285/4596561

Pain A, Böhme U, Berry AE, Mungall K, Finn RD, Jackson AP et al (2008) The genome of the simian and human malaria parasite Plasmodium knowlesi. Nature [Internet] 455(7214):799-803 Available from: http://www.nature.com/doifinder/10.1038/ nature 07306

Pasini EM, Braks JA, Fonager J, Klop O, Aime E, Spaccapelo R et al (2013) Proteomic and genetic analyses demonstrate that Plasmodium berghei blood stages export a large and diverse repertoire of proteins. Mol Cell Proteomics [Internet] 12(2):426-448 Available from: http://www.mcponline.org/lookup/doi/10.1074/ mcp.M112.021238

Pearson RD, Amato R, Auburn S, Miotto O, Almagro-Garcia J, Amaratunga $\mathrm{C}$ et al (2016) Genomic analysis of local variation and recent evolution in Plasmodium vivax. Nat Genet 48(8):959 964

Peng K, Goh YS, Siau A, Franetich J-F, Chia WN, Ong ASM et al (2016) Breadth of humoral response and antigenic targets of sporozoiteinhibitory antibodies associated with sterile protection induced by controlled human malaria infection. Cell Microbiol 18(12):17391750

Penny MA, Verity R, Bever CA, Sauboin C, Galactionova K, Flasche S et al (2016) Public health impact and cost-effectiveness of the RTS, S/AS01 malaria vaccine: a systematic comparison of predictions from four mathematical models. Lancet 387(10016):367-375 
Peterson DS, Walliker D, Wellems TE (1988) Evidence that a point mutation in dihydrofolate reductase-thymidylate synthase confers resistance to pyrimethamine in falciparum malaria. Proc Natl Acad Sci U S A 85(23):9114-9118

Phillips MA, Burrows JN, Manyando C, Van Huijsduijnen RH, Van Voorhis WC, Wells TNC (2017) Malaria. Nat Rev Dis Prim 3

Pirahmadi S, Zakeri S, Mehrizi AA, Djadid ND (2018) Analysis of genetic diversity and population structure of gene encoding celltraversal protein for ookinetes and sporozoites (CelTOS) vaccine candidate antigen in global Plasmodium falciparum populations. Infect Genet Evol [Internet] 59(July 2017):113-125. https://doi. org/10.1016/j.meegid.2018.01.023

Plowe CV, Kublin JG, Doumbo OKP (1998) falciparum dihydrofolate reductase and dihydropteroate synthase mutations: epidemiology and role in clinical resistance to antifolates. Drug Resistance Updates 1:389-396

Pradel G (2007) Proteins of the malaria parasite sexual stages: expression, function and potential for transmission blocking strategies. Parasitology 134:1911-1929

Del Prete S, Vullo D, Fisher GM, Andrews KT, Poulsen S-A, Capasso C et al (2014) Discovery of a new family of carbonic anhydrases in the malaria pathogen Plasmodium falciparum-the $\eta$-carbonic anhydrases. Bioorg Med Chem Lett [Internet] 24(18):4389-4396 Available from: http://linkinghub.elsevier.com/retrieve/pii/ S0960894X14008464

Price RN, Uhlemann AC, Brockman A, McGready R, Ashley E, Phaipun $\mathrm{L}$ et al (2004) Mefloquine resistance in Plasmodium falciparum and increased pfmdr1 gene copy number. Lancet 364(9432):438-447

Quispe AM, Pozo E, Guerrero E, Durand S, Baldeviano GC, Edgel KA et al (2014) Plasmodium vivax hospitalizations in a monoendemic malaria region: severe vivax malaria? Am J Trop Med Hyg. 91(1): $11-17$

Ranford-Cartwright LC, Mwangi JM (2012) Analysis of malaria parasite phenotypes using experimental genetic crosses of Plasmodium falciparum. Int J Parasitol 42:529-534

Reed MB, Saliba KJ, Caruana SR, Kirk K, Cowman AF (2000) Pgh1 modulates sensitivity and resistance to multiple antimalarials in Plasmodium falciparum. Nature 403(6772):906-909

Richards JS, Arumugam TU, Reiling L, Healer J, Hodder AN, Fowkes FJI et al (2013) Identification and prioritization of merozoite antigens as targets of protective human immunity to Plasmodium falciparum malaria for vaccine and biomarker development. J Immunol [Internet] 191(2):795-809 Available from: http://www. jimmunol.org/cgi/doi/10.4049/jimmunol.1300778

Richards JS, MacDonald NJ, Eisen DP (2006) Limited polymorphism in Plasmodium falciparum ookinete surface antigen, von Willebrand factor A domain-related protein from clinical isolates. Malar J 5

Richie TL, Billingsley PF, Sim BKL, James ER, Chakravarty S, Epstein JE et al (2015) Progress with Plasmodium falciparum sporozoite (PfSPZ)-based malaria vaccines. Vaccine [Internet] 33(52):74527461 Available from: https://doi.org/10.1016/j.vaccine.2015.09.096

Rieckmann KH, Beaudoin RL, Cassells JS, Sell KW (1979) Use of attenuated sporozoites in the immunization of human volunteers against falciparum malaria. Bull World Health Organ 57(Suppl. 1): 261-265

Roca-Feltrer A, Carneiro I, Smith L, Schellenberg JRA, Greenwood B, Schellenberg D (2010) The age patterns of severe malaria syndromes in sub-Saharan Africa across a range of transmission intensities and seasonality settings. Malar J 9(1)

Roepe PD (2009) Molecular and physiologic basis of quinoline drug resistance in Plasmodium falciparum malaria. Future Microbiol [Internet] 4(4):441-455 Available from: http://www. futuremedicine.com/doi/10.2217/fmb.09.15

Roestenberg M, Teirlinck AC, McCall MBB, Teelen K, Makamdop KN, Wiersma $\mathrm{J}$ et al (2011) Long-term protection against malaria after experimental sporozoite inoculation: an open-label follow-up study. Lancet 377(9779):1770-1776

Rojo-marcos G. (2011) Infección por Plasmodium ovale: descripción de 16 casos y revisión del tema 29(3):204-8

Rovira-Graells N, Gupta AP, Planet E, Crowley VM, Mok S, De Pouplana LR et al (2012) Transcriptional variation in the malaria parasite Plasmodium falciparum. Genome Res 22(5):925-938

Rutledge GG, Böhme U, Sanders M, Reid AJ, Cotton JA, MaigaAscofare $\mathrm{O}$ et al (2017) Plasmodium malariae and P. ovale genomes provide insights into malaria parasite evolution. Nature [Internet] 542(7639):101-104 Available from: http://www.nature.com/ doifinder/10.1038/nature21038

Sá JM, Nomura T, Neves JDA, Baird JK, Wellems TE, Del Portillo HA (2005) Plasmodium vivax: allele variants of the mdr1 gene do not associate with chloroquine resistance among isolates from Brazil, Papua, and monkey-adapted strains. Exp Parasitol 109(4):256-259

Sack B, Kappe SHI, Sather DN (2017) Towards functional antibodybased vaccines to prevent pre-erythrocytic malaria infection. Expert Rev Vaccines 16(5):403-414

Saini E, Zeeshan M, Brady D, Pandey R, Kaiser G, Koreny L, et al. (2017) Photosensitized INA-labelled protein 1 (PhIL1) is novel component of the inner membrane complex and is required for Plasmodium parasite development. Sci Rep 7(1)

Sargeant TJ, Marti M, Caler E, Carlton JM, Simpson K, Speed TP et al (2006) Lineage-specific expansion of proteins exported to erythrocytes in malaria parasites. Genome Biol [Internet] 7(2):R12 Available from: http://www.ncbi.nlm.nih.gov/pubmed/16507167\% 5Cn, http://www.ncbi.nlm.nih.gov/pmc/articles/PMC1431722/pdf/ gb-2006-7-2-r12.pdf

Sastry M, Zhang B, Chen M, Joyce MG, Kong WP, Chuang GY, et al. (2017) Adjuvants and the vaccine response to the DS-Cav1stabilized fusion glycoprotein of respiratory syncytial virus. PLoS One 12(10)

Sattabongkot J, Tsuboi T, Hisaeda H, Tachibana M, Suwanabun N, Rungruang $\mathrm{T}$ et al (2003) Blocking of transmission to mosquitoes by antibody to Plasmodium vivax malaria vaccine candidates PVS25 and PVS28 despite antigenic polymorphism in field isolates. Am J Trop Med Hyg. 69(5):536-541

Saxena AK, Wu Y, Garboczi DN (2007) Plasmodium P25 and P28 surface proteins: potential transmission-blocking vaccines. Eukaryotic Cell 6:1260-1265

van Schaijk BCL, van Dijk MR, van de Vegte-Bolmer M, van Gemert GJ, van Dooren MW, Eksi S et al (2006) Pfs47, paralog of the male fertility factor Pfs $48 / 45$, is a female specific surface protein in Plasmodium falciparum. Mol Biochem Parasitol 149(2):216-222

van Schaijk BCL, Ploemen IHJ, Annoura T, Vos MW, Foquet L, van Gemert G-J et al (2014) A genetically attenuated malaria vaccine candidate based on P. falciparum b9/slarp gene-deficient sporozoites. Elife 3:e03582

Schneider P, Bousema JT, Gouagna LC, Otieno S, Van De Vegte-Bolmer M, Omar SA et al (2007) Submicroscopic Plasmodium falciparum gametocyte densities frequently result in mosquito infection. Am J Trop Med Hyg 76(3):470-474

Scholz M, Fraunholz MJ (2008) A computational model of gene expression reveals early transcriptional events at the subtelomeric regions of the malaria parasite, Plasmodium falciparum. Genome Biol 9(5): R88

Scuracchio P, Vieira SD, Dourado DA, Bueno LM, Colella R, RamosSanchez EM et al (2011) Transfusion-transmitted malaria: case report of asymptomatic donor harboring Plasmodium malariae. Rev Inst Med Trop Sao Paulo 53(1):55-59

Setiadi W, Sudoyo H, Trimarsanto H, Sihite BA, Saragih RJ, Juliawaty R, et al. (2016) A zoonotic human infection with simian malaria, Plasmodium knowlesi, in Central Kalimantan, Indonesia. Malar J $15(1)$ 
Seydel KB, Kampondeni SD, Valim C, Potchen MJ, Milner DA, Muwalo FW et al (2015) Brain swelling and death in children with cerebral malaria. N Engl J Med 372(12):1126-1137

Siau A, Silvie O, Franetich JF, Yalaoui S, Marinach C, Hannoun L, et al. (2008) Temperature shift and host cell contact up-regulate sporozoite expression of Plasmodium falciparum genes involved in hepatocyte infection. PLoS Pathog 4(8)

Sidhu ABS, Uhlemann A, Valderramos SG, Valderramos J, Krishna S, Fidock DA (2006) Decreasing pfmdrl copy number in Plasmodium falciparum malaria heightens susceptibility to mefloquine, lumefantrine, halofantrine, quinine, and artemisinin. J Infect Dis [Internet] 194(4):528-535 Available from: https://academic.oup. com/jid/article-lookup/doi/10.1086/507115

Silvie O, Mota MM, Matuschewski K, Prudêncio M (2008) Interactions of the malaria parasite and its mammalian host. Curr Opin Microbiol $11: 352-359$

Sinden RE (2015) The cell biology of malaria infection of mosquito: advances and opportunities. Cell Microbiol 17(4):451-466

Singh B, Sung LK, Matusop A, Radhakrishnan A, Shamsul SS, CoxSingh J et al (2004a) A large focus of naturally acquired Plasmodium knowlesi infections in human beings. Lancet 363(9414):1017-1024

Singh B, Sung LK, Matusop A, Radhakrishnan A, Shamsul SSG, CoxSingh J et al (2004b) A large focus of naturally acquired Plasmodium knowlesi infections in human beings. Lancet 363(9414):1017-1024

Sinka ME, Bangs MJ, Manguin S, Rubio-Palis Y, Chareonviriyaphap T, Coetzee M, et al. (2012) A global map of dominant malaria vectors. Parasites Vectors 5(1)

Siqueira AM, Mesones-Lapouble O, Marchesini P, de Sampaio V, S, Brasil P, Tauil PL et al (2016) Plasmodium vivax landscape in Brazil: scenario and challenges. Am J Trop Med Hyg 95(6 Suppl): 87-96

Sirima SB, Mordmüller B, Milligan P, Ngoa UA, Kironde F, Atuguba F et al (2016) A phase 2b randomized, controlled trial of the efficacy of the GMZ2 malaria vaccine in African children. Vaccine 34(38): $4536-4542$

Skinner J, Huang CY, Waisberg M, Felgner PL, Doumbo OK, Ongoib A et al (2015) Plasmodium falciparum gametocyte-specific antibody profiling reveals boosting through natural infection and identifies potential markers of gametocyte exposure. Infect Immun 83(11): 4229-4236

Smith RC, Vega-Rodríguez J, Jacobs-Lorena M (2014) The Plasmodium bottleneck: malaria parasite losses in the mosquito vector. Mem Inst Oswaldo Cruz 109(5):644-661

Snounou G, Viriyakosol S, Zhu XP, Jarra W, Pinheiro L, do Rosario VE et al (1993) High sensitivity of detection of human malaria parasites by the use of nested polymerase chain reaction. Mol Biochem Parasitol 61(2):315-320

Srisutham S, Saralamba N, Sriprawat K, Mayxay M, Smithuis F, Nosten $F$ et al (2018) Genetic diversity of three surface protein genes in Plasmodium malariae from three Asian countries. Malar J [Internet] 17(1):24. https://doi.org/10.1186/s12936-018-2176-x

Stephens JWW (1922) A new malaria parasite of man. Ann Trop Med Parasitol 16(1):383-388

Sulistyaningsih E, Fitri LE, Löscher T, Berens-Riha N (2010 Jun) Diagnostic difficulties with Plasmodium knowlesi infection in humans. Emerg Infect Dis 16(6):1033-1034

Sutherland CJ, Polley SD (2011) Genomic insights into the past, current and future evolution of human parasites of the genus Plasmodium. In: Genetics and Evolution of Infectious Diseases. p. 607-35

Sutherland CJ, Tanomsing N, Nolder D, Oguike M, Jennison C, Pukrittayakamee S et al (2010) Two nonrecombining sympatric forms of the human malaria parasite Plasmodium ovale occur globally. J Infect Dis 201(10):1544-1550
Ta TH, Hisam S, Lanza M, Jiram AI, Ismail N, Rubio JM (2014) First case of a naturally acquired human infection with Plasmodium cynomolgi. Malar J 13(1):68

Tachibana M, Sato C, Otsuki H, Sattabongkot J, Kaneko O, Torii M et al (2012) Plasmodium vivax gametocyte protein Pvs230 is a transmission-blocking vaccine candidate. Vaccine 30(10):18071812

Tachibana M, Suwanabun N, Kaneko O, Iriko H, Otsuki H, Sattabongkot $\mathrm{J}$ et al (2015) Plasmodium vivax gametocyte proteins, Pvs48/45 and Pvs47, induce transmission-reducing antibodies by DNA immunization. Vaccine 33(16):1901-1908

Tachibana M, Tsuboi T, Kaneko O, Khuntirat B, Torii M (2002) Two types of Plasmodium ovale defined by SSU rRNA have distinct sequences for ookinete surface proteins. Mol Biochem Parasitol 122(2):223-226

Tachibana M, Tsuboi T, Templeton TJ, Kaneko O, Torii M (2001) Presence of three distinct ookinete surface protein genes, Pos25, Pos28-1, and Pos28-2, in Plasmodium ovale. Mol Biochem Parasitol 113(2):341-344

Talundzic E, Ravishankar S, Nayak V, Patel DS, Olsen C, Sheth M et al (2017) First full draft genome sequence of Plasmodium brasilianum. Genome Announc [Internet] 5(6):e01566-e01516 Available from: http://www.ncbi.nlm.nih.gov/pubmed/28183758\%5Cn, http:// www.pubmedcentral.nih.gov/articlerender.fcgi?artid= PMC5331498

Tangpukdee N, Duangdee C, Wilairatana P, Krudsood S (2009) Malaria diagnosis: a brief review. Korean J Parasitol [Internet] 47(2):93-102 Available from: http://www.ncbi.nlm.nih.gov/pubmed/19488414\% 5Cn, http://www.pubmedcentral.nih.gov/articlerender.fcgi?artid= PMC2688806

Tarr SJ, Moon RW, Hardege I, Osborne AR (2014) A conserved domain targets exported PHISTb family proteins to the periphery of Plasmodium infected erythrocytes. Mol Biochem Parasitol 196(1): $29-40$

Templeton TJ, Kaslow DC, Fidock DA (2000) Developmental arrest of the human malaria parasite Plasmodium falciparum within the mosquito midgut via CTRP gene disruption. Mol Microbiol [Internet] 36(1):1-9 Available from: http://www.ncbi.nlm.nih.gov/pubmed/ 10760158

Tham W-H, Beeson JG, Rayner JC (2017) Plasmodium vivax vaccine research — we've only just begun. Int J Parasitol 47(2-3):111-118

Thera MA, Doumbo OK, Coulibaly D, Laurens MB, Ouattara A, Kone AK et al (2011) A field trial to assess a blood-stage malaria vaccine. N Engl J Med [Internet] 365(11):1004-1013 Available from: http:// www.ncbi.nlm.nih.gov/pubmed/21916638\%5Cn, http://www. pubmedcentral.nih.gov/articlerender.fcgi?artid=PMC3242358

Tolia NH, Enemark EJ, Sim BKL, Joshua-Tor L (2005 Jul) Structural basis for the EBA-175 erythrocyte invasion pathway of the malaria parasite Plasmodium falciparum. Cell 122(2):183-193

Triglia T, Cowman AF (1994) Primary structure and expression of the dihydropteroate synthetase gene of Plasmodium falciparum. Proc Natl Acad Sci U S A [Internet] 91(15):7149-7153 Available from: http://www.pubmedcentral.nih.gov/articlerender.fcgi?artid= 44356\&tool=pmcentrez\&rendertype $=$ abstract

Trottein F, Triglia T, Cowman AF (1995) Molecular cloning of a gene from Plasmodium falciparum that codes for a protein sharing motifs found in adhesive molecules from mammals and Plasmodia. Mol Biochem Parasitol 74(2):129-141

Tuju J, Kamuyu G, Murungi LM, Osier FHA (2017) Vaccine candidate discovery for the next generation of malaria vaccines. Immunology 152:195-206

Tymoshenko S, Oppenheim RD, Soldati-Favre D, Hatzimanikatis V (2013) Functional genomics of plasmodium falciparum using metabolic modelling and analysis. Brief Funct Genomics 12(4):316327 
Vaidya AB, Akella R, Suplick K (1989) Sequences similar to genes for two mitochondrial proteins and portions of ribosomal RNA in tandemly arrayed 6-kilobase-pair DNA of a malarial parasite. Mol Biochem Parasitol 35(2):97-107

Vallejo AF, Martinez NL, Tobon A, Alger J, Lacerda M V., Kajava A V., et al. (2016) Global genetic diversity of the Plasmodium vivax transmission-blocking vaccine candidate Pvs48/45. Malar J 15(1)

Venkatraman N, Anagnostou N, Bliss C, Bowyer G, Wright D, LövgrenBengtsson K et al (2017) Safety and immunogenicity of heterologous prime-boost immunization with viral-vectored malaria vaccines adjuvanted with matrix-M ${ }^{\mathrm{TM}}$. Vaccine 35(45):6208-6217

Volz JC, Yap A, Sisquella X, Thompson JK, Lim NTY, Whitehead LW et al (2016) Essential role of the PfRh5/PfRipr/CyRPA complex during Plasmodium falciparum invasion of erythrocytes. Cell Host Microbe 20(1):60-71

Voss TS, Healer J, Marty AJ, Duffy MF, Thompson JK, Beeson JG, et al. (2005) A var gene promoter controls allelic exclusion of virulence genes in Plasmodium falciparum malaria. Nature [Internet]. Available from: http://www.nature.com/doifinder/10.1038/ nature 04407

Wang B, Lu F, Cheng Y, Chen JH, Jeon HY, Ha KS et al (2015) Immunoprofiling of the tryptophan-rich antigen family in Plasmodium vivax. Infect Immun 83(8):3083-3095

Wang P, Read M, Sims PF, Hyde JE (1997) Sulfadoxine resistance in the human malaria parasite Plasmodium falciparum is determined by mutations in dihydropteroate synthetase and an additional factor associated with folate utilization. Mol Microbiol 23(5):979-986

Warncke JD, Vakonakis I, Beck H-P (2016) Plasmodium helical interspersed subtelomeric (PHIST) proteins, at the center of host cell remodeling. Microbiol Mol Biol Rev [Internet] 80(4):905-927. https://doi.org/10.1128/MMBR.00014-16

Wassmer SC, Taylor TE, Rathod PK, Mishra SK, Mohanty S, ArevaloHerrera $M$ et al (2015) Investigating the pathogenesis of severe malaria: a multidisciplinary and cross-geographical approach. Am J Trop Med Hyg. 93:42-56

Weiss GE, Gilson PR, Taechalertpaisarn T, Tham WH, de Jong NWM, Harvey KL, et al. (2015) Revealing the sequence and resulting cellular morphology of receptor-ligand interactions during Plasmodium falciparum invasion of erythrocytes. PLoS Pathog 11(2)

White NJ (2008) Plasmodium knowlesi: the fifth human malaria parasite. Clin Infect Dis 46(2):172-173

White NJ, Pukrittayakamee S, Hien TT, Faiz MA, Mokuolu OA, Dondorp AM (2014) Malaria. Lancet (London, England) 383(9918):723-35

WHO (2014) Severe malaria section 1: epidemiology of severe falciparum malaria. Trop Med Int Heal 19 (suppl.:7-13

WHO. Artemisinin and artemisinin-based combination therapy resistance. 2016;(October):1-8. Available from: http://apps.who.int/iris/ bitstream/10665/208820/1/WHO_HTM_GMP_2016.5_eng.pdf? ua $=1$
Wilby KJ, Lau TTY, Gilchrist SE, Ensom MHH. Mosquirix (RTS,S): a novel vaccine for the prevention of Plasmodium falciparum malaria. Ann Pharmacother [Internet] 2012;46(3):384-393. Available from: http://aop.sagepub.com/content/46/3/384.full

William T, Rahman HA, Jelip J, Ibrahim MY, Menon J, Grigg MJ, et al. (2013) Increasing incidence of Plasmodium knowlesi malaria following control of P. falciparum and P. vivax malaria in Sabah, Malaysia. Baird JK, editor. PLoS Negl Trop Dis 7(1):e2026

Williams TN (2012) Balancing act: haemoglobinopathies and malaria. Lancet Infect Dis 12(6):427-428

Williamson KC, Keister DB, Muratova O, Kaslow DC (1995) Recombinant Pfs230, a Plasmodium falciparum gametocyte protein, induces antisera that reduce the infectivity of Plasmodium falciparum to mosquitoes. Mol Biochem Parasitol 75(1):33-42

Winter DJ, Pacheco MA, Vallejo AF, Schwartz RS, Arevalo-Herrera M, Herrera S, et al. (2015) Whole genome sequencing of field isolates reveals extensive genetic diversity in Plasmodium vivax from Colombia. PLoS Negl Trop Dis 9(12)

Winter G, Kawai S, Haeggström M, Kaneko O, von Euler A, Kawazu S et al (2005) SURFIN is a polymorphic antigen expressed on Plasmodium falciparum merozoites and infected erythrocytes. J Exp Med [Internet] 201(11):1853-1863 Available from: http:// www.ncbi.nlm.nih.gov/pubmed/15939796\%5Cn, http://www. pubmedcentral.nih.gov/articlerender.fcgi?artid=PMC2213267

Wirth CC, Bennink S, Scheuermayer M, Fischer R, Pradel G (2015) Perforin-like protein PPLP4 is crucial for mosquito midgut infection by Plasmodium falciparum. Mol Biochem Parasitol 201(2):90-99

World Health Organization W, WHO, World Health Organization W. World malaria report 2015. World Health. 2015;1-280

Wykes MN, Horne-Debets JM, Leow CY, Karunarathne DS (2014) Malaria drives T cells to exhaustion. Front Microbiol Vol. 5

Yam XY, Brugat T, Siau A, Lawton J, Wong DS, Farah A et al (2016) Characterization of the Plasmodium interspersed repeats (PIR) proteins of Plasmodium chabaudi indicates functional diversity. Sci Rep 6

Yang ASP, Lopaticki S, O'Neill MT, Erickson SM, Douglas DN, Kneteman NM, et al. (2017) AMA1 and MAEBL are important for Plasmodium falciparum sporozoite infection of the liver. Cell Microbiol 19(9)

Yusof R, Lau Y, Mahmud R, Fong M, Jelip J, Ngian H et al (2014) High proportion of knowlesi malaria in recent malaria cases in Malaysia. Malar J 13(1):168

Zaw MT, Lin Z (2017) Two sympatric types of Plasmodium ovale and discrimination by molecular methods. J Microbiol Immunol Infect 50(5):559-564

Zhang Q, Ma C, Oberli A, Zinz A, Engels S, Przyborski JM (2017) Proteomic analysis of exported chaperone/co-chaperone complexes of $\mathrm{P}$. falciparum reveals an array of complex protein-protein interactions. Sci Rep; 7

Zimmerman PA, Mehlotra RK, Kasehagen LJ, Kazura JW (2004) Why do we need to know more about mixed Plasmodium species infections in humans? Trends Parasitol 20(9):440-447 